
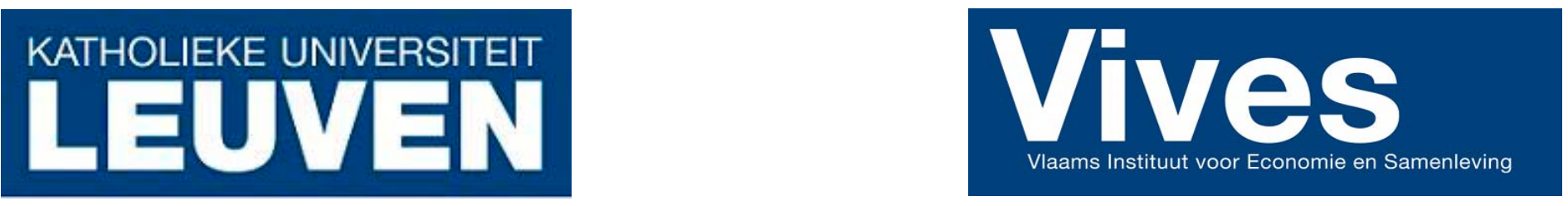

Naamsestraat 61 - bus 3550 B-3000 Leuven - BELGIUM Tel : 32-16-326661 vives@econ.kuleuven.be

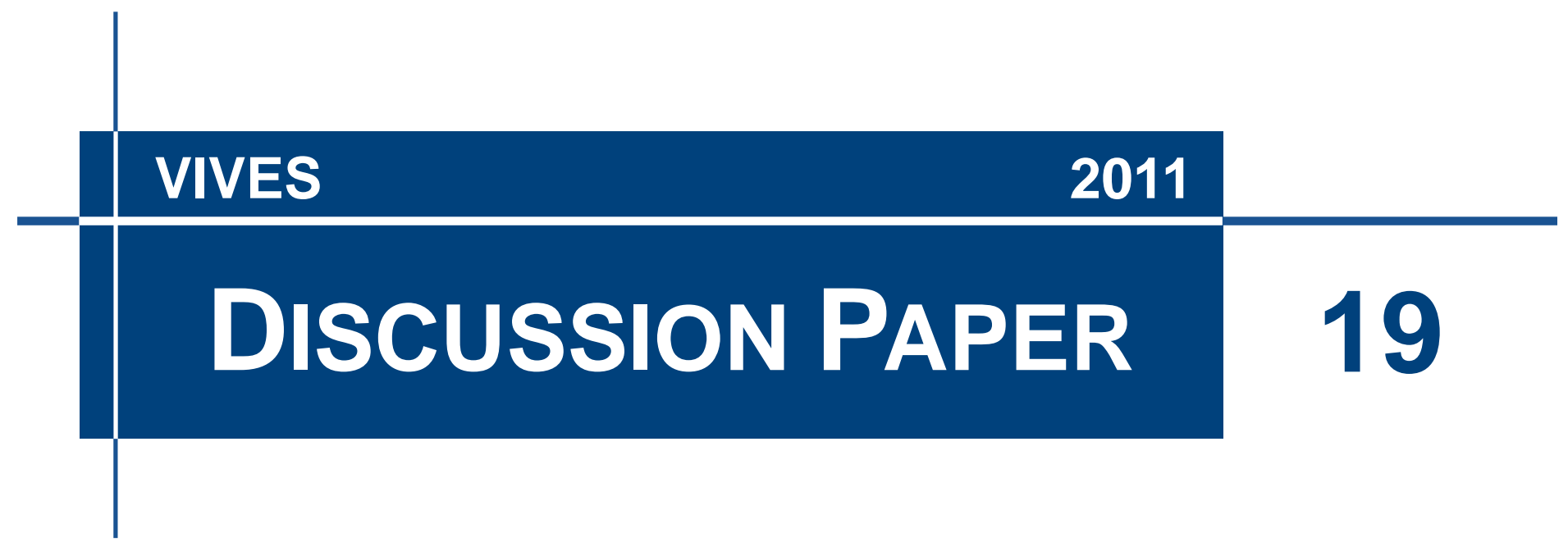

\title{
Urban Accounting and Welfare
}

\author{
Klaus Desmet \\ Esteban Rossi-Hansberg
}

Copyright (c) 2010 by K.U.LEUVEN, VIVES. Discussion papers are in draft form. This discussion paper is distributed for purposes of comment and discussion only. It may not be reproduced without permission of the copyright holder. 


\title{
Urban Accounting and Welfare*
}

\author{
Klaus Desmet \\ Universidad Carlos III
}

\author{
Esteban Rossi-Hansberg \\ Princeton University
}

March 11, 2011

\begin{abstract}
This paper proposes a simple theory of a system of cities that decomposes the determinants of the city size distribution into three main components: efficiency, amenities, and frictions. Higher efficiency and better amenities lead to larger cities, but also to greater frictions through congestion and other negative effects of agglomeration. Using data on MSAs in the United States, we parameterize the model and empirically estimate efficiency, amenities and frictions. Counterfactual exercises show that all three characteristics are important in that eliminating any of them leads to large population reallocations, though the welfare effects from these reallocations are small. Overall, we find that the gains from worker mobility across cities are modest. When we introduce externalities, we find an important city selection effect: eliminating differences in any of the city characteristics causes many cities to exit. We apply the same methodology to Chinese cities and find welfare effects that are many times larger than those in the U.S.
\end{abstract}

\section{INTRODUCTION}

Why do people live in particular cities? We can list many reasons, but two are undoubtedly relevant. Agents can enjoy the city or be more productive there. How many agents are attracted to a particular city due to its combination of life amenities and the productivity level of its workforce determines the size of cities. The positive effects of amenities and high productivity are capped by the costs and frictions arising from congestion. Depending on city governance and the flexibility of markets, these costs and frictions can be more or less important. These city characteristics are in turn enhanced and amplified by the presence of urban externalities. Understanding the different

\footnotetext{
${ }^{*}$ We thank Kristian Behrens, Gilles Duranton, Wolfgang Keller, and Stephen Redding for helpful comments, and Joseph Gomes and Xuexin Wang for excellent assistance with the data. We acknowledge the financial support of the International Growth Centre at LSE (Grant RA-2009-11-015), the Comunidad de Madrid (PROCIUDAD-CM), the Spanish Ministry of Science (ECO2008-01300) and the Excellence Program of the Bank of Spain.
} 
forces that determine city sizes is crucial for answering a broad set of questions. What is the relative importance of these forces in determining the size distribution of cities? How much would we gain or lose if cities had similar amenities, technology levels, or frictions? How much reallocation would this cause? More generally, what are the welfare implications of the location of agents across cities?

In this paper we provide an easy way of decomposing the characteristics that lead to the size distribution of cities into three main components: efficiency, amenities, and excessive frictions. We use a simple urban theory to calculate these components and to carry out a wide set of counterfactual exercises that provide answers to the questions we asked above. The theory consists of a multi-city model with monocentric cities that produce a single good. Workers decide how much to work and where to live. Efficiency is modeled as TFP, amenities as preference shocks, and frictions as the cost of providing urban infrastructure that is paid for with labor taxes. To measure "excessive frictions," we use the concept of a "labor wedge" (see Chari, et al., 2007) and decompose it into the standard cost effect of city size and the "excessive cost" of providing city services. We solve the general equilibrium model with and without externalities.

We use an empirical strategy to parameterize the model and to obtain the "excessive frictions" and efficiency levels across cities. We then use the model to determine the amenities that make cities be their actual sizes. Therefore, the model matches by construction the size distribution of cities in the U.S. The counterfactual exercises then allow us to analyze the effects of the different parameter values and the different city characteristics. For many counterfactuals we find that the changes in utility (and in consumption) are modest in spite of massive population reallocations. For example, eliminating efficiency differences across cities lowers equilibrium utility levels by a mere $1.2 \%$, and eliminating amenity differences reduces welfare by just $0.2 \%$. When we account for externalities, these numbers decline even further. The welfare implications of redistributing agents across cities due to switching off any of the fundamental characteristics that account for the actual size distribution are never greater than two percentage points. ${ }^{1}$ This is surprising given that the differences across cities in amenities and efficiency levels can be rather large, and given that the implied population reallocations can be as large as $40 \%$. Adding externalities has an important effect on the extensive margin in the counterfactual exercises, with many cities exiting and the urban population settling in the surviving cities. However, these externalities do not increase the welfare effects in the different counterfactual exercises; if anything, the effects are even more modest.

\footnotetext{
${ }^{1}$ This resembles the literature on business cycle accounting that found that eliminating business cycles would lead to trivial effects (as in Lucas, 1987, we do not have the necessary distributional cost to obtain larger losses as agents are identical, as emphasized by Storesletten, et al., 2001).
} 
A relevant question is whether the small welfare effects we uncover are inherent to the model or specific to the U.S. To address this issue, we explore the same type of counterfactual exercises for the size distribution of cities in China. We find welfare effects that are an order of magnitude larger than in the U.S. For example, when eliminating efficiency differences across Chinese cities, welfare increases by $47 \%$, compared to a corresponding $1.2 \%$ in the U.S.

The paper relates to much of the literature on the size distribution of cities, but instead of taking a random growth approach in which city dynamics coming from productivity or preference shocks determine the size distribution (as in Gabaix, 1999a, b, Duranton, 2007, Rossi-Hansberg and Wright 2007, and Cordoba, 2008), we use a model to decompose the individual city characteristics that lead to the cross-sectional distribution of city sizes. Since our model has no mobility frictions or specific factors, agents move across cities as a response to any temporary shock. In that sense, city dynamics play no role in our decomposition. Of course, the measured levels of efficiency, amenities or frictions may still be the result of these dynamic mechanisms. To the extent that this is the case, our approach helps us assess the contribution of particular dynamic factors to the distribution of city sizes.

Further related to our work is Au and Henderson (2006), who use a model with agglomeration economies and congestion effects to analyze optimal city sizes in China. After structurally estimating their model, they calculate the welfare effects of migration constraints and find that output per worker would increase substantially in some cities if labor were free to move. However, different from us, they limit their attention to efficiency and do not focus on the other components determining city size. Finally, a recent working paper by Behrens, Mion, Murata and Südekum (2010) also proposes a general equilibrium model of a system of cities that can be compared with the data. In contrast to our work, their paper emphasizes pro-competitive forces that work through firm selection to determine the productivity of cities. These forces lead to trade between cities, and so their counterfactual exercises focus on how shocks in one city affect the distribution of population and productivities in the rest of the country.

Other work has emphasized the importance of frictions, productivity, and amenities in explaining the distribution of city sizes. Glaeser et al. (2001), Glaeser et al. (2005), Albouy (2008 and 2009), and Rappaport (2008 and 2009), for example, have underscored the importance of city amenities and institutional frictions. Others have emphasized the importance of the relative efficiency in production of the different urban areas (Holmes and Stevens, 2002 and 2004, Holmes, 2005, Duranton and Overman, 2008) or the geographic characteristics of the locations in which cities develop (Davis 
and Weinstein, 2002, Bleakley and Lin, 2010). Our approach relates to this work in that we also aim to identify important city characteristics that lead to urban agglomeration. We differ in that we have a fully specified general equilibrium model that we use to jointly account for efficiency, amenities and excessive frictions. The model is also flexible enough to incorporate externalities in efficiency levels and amenities. With the urban characteristics in hand we can perform a variety of counterfactual exercises and calculate the welfare implications of eliminating variation in any of these characteristics. Furthermore, the proposed methodology can be used to compare urban systems across countries, as we do for the cases of China and the U.S.

The rest of the paper is organized as follows. Section 2 introduces a simple urban model and explains the basic urban accounting exercise. Section 3 estimates a log-linear version of the structural equations using U.S. data between 2005 and 2008 and obtains the reduced-form effects of the three main characteristics of cities on rents and city sizes. Section 4 performs counterfactual exercises using the empirical values of these city characteristics. Section 5 studies the effect of efficiency and amenity shocks. Section 6 applies our methodology to China, and Section 7 concludes. Appendix A shows how the population sizes of individual cities are affected when certain characteristics change. Appendix B describes in detail the urban data set constructed.

\section{THE MODEL}

We use a standard urban model with elastic labor supply so that labor taxes create distortions. Agents work in cities with idiosyncratic productivities and amenities. They live in mono-centric cities that require commuting infrastructures that city governments provide by levying labor taxes. Large cities are more expensive to live in because of higher labor taxes and commuting costs but are large because of high levels of efficiency or local amenities. City governments can be more or less efficient in the provision of the public infrastructure. We refer to this variation as a city's "excessive frictions." In later sections we augment the model to include local externalities in production and amenities.

\subsection{Technology}

Consider a model of a system of cities in an economy with $N_{t}$ workers. Goods are produced in $I$ mono-centric circular cities. Cities have a local level of productivity. Production in a city $i$ in period 
$t$ is given by

$$
Y_{i t}=A_{i t} K_{i t}^{\theta} H_{i t}^{1-\theta}
$$

where $A_{i t}$ denotes city productivity, $K_{i t}$ denotes total capital and $H_{i t}$ denotes total hours worked in the city. ${ }^{2}$ We denote the population size of city $i$ by $N_{i t}$. The standard first-order conditions of this problem are

$$
w_{i t}=(1-\theta) \frac{Y_{i t}}{H_{i t}}=(1-\theta) \frac{y_{i t}}{h_{i t}}
$$

and

$$
r_{t}=\theta \frac{Y_{i t}}{K_{i t}}=\theta \frac{y_{i t}}{k_{i t}}
$$

where small-cap letters denote per capita variables (e.g. $y_{i t}=Y_{i t} / N_{i t}$ ). Note that capital is freely mobile across locations so there is a national interest rate $r_{t}$. Mobility patterns will not be determined solely by the wage, $w_{i t}$, so there may be equilibrium differences in wages across cities at any point in time.

We can then write down the "efficiency wedge," which is identical to the level of productivity, $A_{i t}$, as

$$
A_{i t}=\frac{Y_{i t}}{K_{i t}^{\theta} H_{i t}^{1-\theta}}=\frac{y_{i t}}{k_{i t}^{\theta} h_{i t}^{1-\theta}}
$$

\subsection{Preferences}

Agents order consumption and hour sequences according to the following utility function

$$
\sum_{t=0}^{\infty} \beta^{t}\left[\log c_{i t}+\psi \log \left(1-h_{i t}\right)+\gamma_{i}\right]
$$

where $\gamma_{i}$ is a city-specific amenity and $\psi$ is a parameter that governs the relative preference for leisure. Each agent lives on one unit of land and commutes from his home to work. Commuting is costly in terms of goods.

The problem of an agent in city $i_{0}$ with capital $k_{0}$ is therefore

$$
\max _{\left\{c_{i_{t}}, h_{i_{t}}, k_{i_{t}}, i_{t}\right\}_{t=0}^{\infty}} \sum_{t=0}^{\infty} \beta^{t}\left[\log c_{i t}+\psi \log \left(1-h_{i t}\right)+\gamma_{i}\right]
$$

subject to

$$
\begin{aligned}
c_{i t}+x_{i t} & =r_{t} k_{i t}+w_{i t} h_{i t}\left(1-\tau_{i t}\right)-R_{i t}-T_{i t} \\
k_{i t+1} & =(1-\delta) k_{i t}+x_{i t},
\end{aligned}
$$

\footnotetext{
${ }^{2}$ It would be straightforward to generalize this model to include human capital. We experimented with this, and doing so did not substantially change any of the theoretical or empirical results.
} 
where $x_{i t}$ is investment, $\tau_{i t}$ is a labor tax or friction associated with the cost of building the commuting infrastructure, $R_{i t}$ are land rents and $T_{i t}$ are commuting costs (as we will see below, $R_{i t}+T_{i t}$ is constant in the city so the location of the agent's home does not affect his choices). ${ }^{3}$

Throughout the paper we assume that we are in steady state so $k_{i t+1}=k_{i t}$ and $x_{i t}=\delta k_{i t}$. Furthermore, we assume $k_{i t}$ is such that $r_{t}=\delta$ (capital is at its Golden Rule level). The simplified budget constraint of the agent becomes

$$
c_{i t}=w_{i t} h_{i t}\left(1-\tau_{i t}\right)-R_{i t}-T_{i t} .
$$

The first order conditions of this problem are given by $1 / c_{i t}=\lambda_{i t}$, and

$$
\psi \frac{1}{1-h_{t}}=w_{i t}\left(1-\tau_{i t}\right) \lambda_{i t}
$$

which imply

$$
\psi \frac{c_{i t}}{1-h_{i t}}=\left(1-\tau_{i t}\right) w_{i t}
$$

Combining equations (1) and (4) we obtain

$$
\left(1-\tau_{i t}\right)=\frac{\psi}{(1-\theta)} \frac{c_{i t}}{1-h_{i t}} \frac{h_{i t}}{y_{i t}}
$$

Agents can move freely across cities so utility in each period has to be determined by

$$
\bar{u}=\log c_{i t}+\psi \log \left(1-h_{i t}\right)+\gamma_{i}
$$

for all cities with $N_{i t}>0$, where $\bar{u}$ is the economy-wide per period utility of living in a city.

\subsection{Commuting Costs, Land Rents and City Equilibrium}

Cities are mono-centric, all production happens at the center, and people live in surrounding areas characterized by their distance to the center, $d$. Cities are surrounded by a vast amount of agricultural land that can be freely converted into urban land. We normalize the price of agricultural land to zero. Since land rents are continuous in equilibrium (otherwise there would be arbitrage opportunities), this implies that at the boundary of a city, $\bar{d}$, land rents should be zero as well, namely, $R(\bar{d})=0$. Since all agents in a city are identical, in equilibrium they must be indifferent between where they live in the city, which implies that the total cost of rent plus commuting costs should be identical in all areas of the city. So

$$
R_{i t}(d)+T(d)=T\left(\bar{d}_{i t}\right)=\kappa \bar{d}_{i t}
$$

\footnotetext{
${ }^{3}$ Since agents can move across cities, the subscript $i$ depends on $t$, as written under the maximization sign. To save on notation, we drop this additional subscript.
} 
since $T(d)=\kappa d$ where $\kappa$ denotes commuting costs per mile.

Since everyone lives in one unit of land, $N_{i t}=\bar{d}^{2} \pi$, and so

$$
\bar{d}_{i t}=\left(\frac{N_{i t}}{\pi}\right)^{\frac{1}{2}}
$$

we know that

$$
R_{i t}(d)+T(d)=\kappa\left(\frac{N_{i t}}{\pi}\right)^{\frac{1}{2}} \text { all } d .
$$

This implies that

$$
R_{i t}(d)=\kappa\left(\bar{d}_{i t}-d\right)
$$

and so total land rents in a city of size $N_{i t}$ are given by

$$
T R_{i t}=\int_{0}^{\bar{d}_{i t}}\left(\kappa\left(\bar{d}_{i t}-d\right) d 2 \pi\right) d d=\frac{\pi^{\frac{1}{2}} \kappa}{3} N_{i t}^{\frac{3}{2}} .
$$

Hence, average land rents are equal to

$$
A R_{i t}=\frac{2 \kappa}{3}\left(\frac{N_{i t}}{\pi}\right)^{\frac{1}{2}} .
$$

Taking logs and rearranging terms, we obtain that

$$
\ln \left(N_{i t}\right)=o_{1}+2 \ln A R_{i t}
$$

where $o_{1}$ is a constant.

We can also compute the total miles traveled by commuters in the city, which is given by

$$
T C_{i t}=\int_{0}^{\bar{d}_{i t}}\left(d^{2} 2 \pi\right) d d=\frac{2}{3} \pi^{-\frac{1}{2}} N_{i t}^{\frac{3}{2}}
$$

\subsection{Government Budget Constraint}

The government levies a labor tax, $\tau_{i t}$, to pay for the transportation infrastructure. This tax can also be interpreted as a distortion in the labor market because of the congestion created in a large city. As in Chari et al. (2007), we will refer to $\tau_{i t}$ as the "labor wedge." Let government expenditure be a function of total commuting costs and wages such that

$$
G\left(h_{i t} w_{i t}, T C_{i t}\right)=g_{i t} h_{i t} w_{i t} \kappa T C_{i t}=g_{i t} h_{i t} w_{i t} \kappa \frac{2}{3} \pi^{-\frac{1}{2}} N_{i t}^{\frac{3}{2}} .
$$

where $g_{i t}$ is a measure of government inefficiency. That is, the government requires $\kappa g_{i t}$ workers per mile commuted to build and maintain urban infrastructure. The government budget constraint is then given by

$$
\tau_{i t} h_{i t} N_{i t} w_{i t}=g_{i t} h_{i t} w_{i t} \kappa \frac{2}{3} \pi^{-\frac{1}{2}} N_{i t}^{\frac{3}{2}}
$$


which implies that the "labor wedge" can be written as

$$
\tau_{i t}=g_{i t} \kappa \frac{2}{3}\left(\frac{N_{i t}}{\pi}\right)^{\frac{1}{2}}
$$

or

$$
\ln \tau_{i t}=o_{2}+\ln g_{i t}+\frac{1}{2} \ln N_{i t} .
$$

\subsection{Equilibrium}

The consumer budget constraint is given by

$$
c_{i t}=w_{i t} h_{i t}\left(1-\tau_{i t}\right)-R_{i t}-T_{i t}=(1-\theta)\left(1-\tau_{i t}\right) y_{i t}-\kappa\left(\frac{N_{i t}}{\pi}\right)^{\frac{1}{2}} .
$$

From (5) we know that

$$
\left(1-\tau_{i t}\right)=\frac{\psi}{(1-\theta)} \frac{c_{i t}}{1-h_{i t}} \frac{h_{i t}}{y_{i t}}
$$

To determine output we know that the production function is given by $y_{i t}=A_{i t} k_{i t}^{\theta} h_{i t}^{1-\theta}$ and the decision of firms to rent capital implies that $r_{t} k_{i t}=\theta y_{i t}$. Hence,

$$
y_{i t}=A_{i t}\left(\frac{\theta y_{i t}}{r_{t}}\right)^{\theta} h_{i t}^{1-\theta}
$$

or

$$
y_{i t}=A_{i t}^{\frac{1}{1-\theta}}\left(\frac{\theta}{r_{t}}\right)^{\frac{\theta}{1-\theta}} h_{i t} .
$$

Hence,

$$
1-h_{i t}=c_{i t} \frac{\psi}{(1-\theta)} \frac{\left(\frac{r_{t}}{\theta}\right)^{\frac{\theta}{1-\theta}}}{\left(1-\tau_{i t}\right) A_{i t}^{\frac{1}{1-\theta}}}
$$

and so

$$
h_{i t}=\frac{1}{1+\psi}\left(1+\frac{\psi\left(R_{i t}+T_{i t}\right)}{(1-\theta)\left(1-\tau_{i t}\right)} \frac{\left(\frac{r_{t}}{\theta}\right)^{\frac{\theta}{1-\theta}}}{A_{i t}^{\frac{1}{1-\theta}}}\right) .
$$

which implies

$$
1-h_{i t}=\frac{\psi}{1+\psi}\left(1-\frac{\left(R_{i t}+T_{i t}\right)}{(1-\theta)\left(1-\tau_{i t}\right)} \frac{\left(\frac{r_{t}}{\theta}\right)^{\frac{\theta}{1-\theta}}}{A_{i t}^{\frac{1}{1-\theta}}}\right)
$$

and

$$
c_{i t}=\frac{(1-\theta)\left(1-\tau_{i t}\right) A_{i t}^{\frac{1}{1-\theta}}\left(\frac{\theta}{r_{t}}\right)^{\frac{\theta}{1-\theta}}-\left(R_{i t}+T_{i t}\right)}{1+\psi} .
$$


The free mobility assumption in (6) implies that $\bar{u}=\log c_{i t}+\psi \log \left(1-h_{i t}\right)+\gamma_{i t}$ for some $\bar{u}_{t}$ determined in general equilibrium so

$$
\begin{aligned}
& \bar{u}_{t}+(1+\psi) \log (1+\psi)-\psi \log \psi \\
= & \log \left((1-\theta)\left(1-\tau_{i t}\right) \frac{A_{i t}^{\frac{1}{1-\theta}}}{\left(\frac{r_{t}}{\theta}\right)^{\frac{\theta}{1-\theta}}}-\left(R_{i t}+T_{i t}\right)\right) \\
& +\psi \log \left(1-\frac{\left(R_{i t}+T_{i t}\right)}{(1-\theta)\left(1-\tau_{i t}\right)} \frac{\left(\frac{r_{t}}{\theta}\right)^{\frac{\theta}{1-\theta}}}{A_{i t}^{\frac{1}{1-\theta}}}\right)+\gamma_{i} \\
= & \log \left((1-\theta)\left(1-\kappa g_{i t} \frac{2}{3}\left(\frac{N_{i t}}{\pi}\right)^{\frac{1}{2}}\right) \frac{A_{i t}^{\frac{1}{1-\theta}}}{\left(\frac{r_{t}}{\theta}\right)^{\frac{\theta}{1-\theta}}}-\kappa\left(\frac{N_{i t}}{\pi}\right)^{\frac{1}{2}}\right) \\
& +\psi \log \left(1-\frac{\left.N_{i t}\right)^{\frac{1}{2}}}{(1-\theta)\left(1-\kappa g_{i t} \frac{2}{3}\left(\frac{N_{i t}}{\pi}\right)^{\frac{1}{2}}\right)} \frac{\left(\frac{r_{t}}{\theta}\right)^{\frac{\theta}{1-\theta}}}{A_{i t}^{\frac{1}{1-\theta}}}\right)+\gamma_{i}
\end{aligned}
$$

The last equation determines the size of the city $N_{i t}$ as an implicit function of city productivity, $A_{i t}$, city amenities, $\gamma_{i}$, government inefficiency $g_{i t}$, and economy-wide variables like $r_{t}$ and $\bar{u}_{t}$. We can use this equation to derive the effect of the three city-specific characteristics $\left(A_{i t}, \gamma_{i t}, g_{i t}\right)$ on $N_{i t}$. First note that the LHS of (11) is decreasing in $N_{i t}$. The LHS is also increasing in $A_{i t}$ and $\gamma_{i}$ and decreasing in $g_{i t}$. Hence, we can prove immediately that

$$
\begin{aligned}
& \frac{d N_{i t}}{d A_{i t}}>0, \\
& \frac{d N_{i t}}{d \gamma_{i}}>0, \\
& \frac{d N_{i t}}{d g_{i t}}<0 .
\end{aligned}
$$

So population increases in a more productive city or a city with more amenities, but it decreases in a city with a less efficient government.

The economy-wide utility level $\bar{u}_{t}$ is determined by the labor market clearing condition

$$
\sum_{i=1}^{I} N_{i t}=N_{t} .
$$

This last equation clarifies that our urban system is closed; we do not consider urban-rural migration. 


\section{EVIDENCE OF EFFICIENCY, AMENITIES AND FRICTIONS}

To lend validity to our theoretical model, we estimate the size of the three derivatives in (12) and estimate the effect of land rents on population as in (7). When doing so, the general equilibrium nature of the model will be key.

\subsection{Empirical Approach}

We first estimate the "labor wedge" using equation (5) and the "efficiency wedge" in equation (2). Note that the empirical measure of the "efficiency wedge" is related not just to productivity, but also to the relative price of city output. Although we have no way of disentangling these two terms, in a theory with multiple goods, relative price effects across cities would have isomorphic effects to changes in productivity. Hence, we just equate productivity to our measure of the "efficiency wedge."

The general equilibrium nature of the model is important. For example, if we regress the $\log$ of city size on the log of the labor wedge, we find a statistically significant positive effect (coefficient of 1.2360 and p-value of 0.000 ). But it would be wrong to conclude from there that higher frictions lead to greater city size. Rather, according to the theory, this positive association would reflect more productive cities being larger, and larger cities experiencing greater commuting costs. That is, in as far as greater commuting costs are due to cities being more efficient, they will be positively associated with city size. Only frictions "in excess" of this basic trade-off between efficiency and congestion will have a negative effect on city size. In what follows we propose a methodology that accounts for these general equilibrium links by decomposing these different effects.

We start by estimating the following equation

$$
\ln N_{i t}=\alpha_{1}+\beta_{1} \ln A_{i t}+\varepsilon_{1 i t}
$$

The value of $\beta_{1}$ yields the effect of the "efficiency wedge" on city population. According to the model, $\beta_{1}>0$ by (12). Furthermore, $\ln \tilde{N}_{i t}\left(A_{i t}\right)=\beta_{1} \ln A_{i t}$ is the population size explained by the size of the "efficiency wedge." In contrast, $\varepsilon_{1 i t}$ is the part of the observed population in the city that is unrelated to productivity; according to the model it is related to both $g_{i t}$ and $\gamma_{i t}$. We can thus define the function $\tilde{\varepsilon}_{1}\left(g_{i t}, \gamma_{i t}\right) \equiv \varepsilon_{1 i t}$.

Since the "efficiency wedge" increases population size, total commuting increases, which affects the "labor wedge" according to equation (10). This is the standard urban trade-off between productivity 
and agglomeration. We can estimate the effect of productivity on the "labor wedge" by using equation (10) and the decomposition of $\ln N_{i t}$ into $\ln \tilde{N}_{i t}\left(A_{i t}\right)$ and $\varepsilon_{1 i t}$ provided by equation (14). Hence, we estimate

$$
\ln \tau_{i t}=\alpha_{2}+\beta_{2} \ln \tilde{N}_{i t}\left(A_{i t}\right)+\varepsilon_{2 i t}
$$

According to equation (10), $\beta_{2}>0$. That is, a city that is more productive and so has more population will be more distorted. We denote the effect of efficiency on distortions by $\ln \widetilde{\tau_{i t}}=$ $\beta_{2} \ln \tilde{N}_{i t}\left(A_{i t}\right)$. Equation (10) also implies that the error term $\varepsilon_{2 i t}$ is related to $g_{i t}$ and to $\tilde{\varepsilon}_{1}\left(g_{i t}, \gamma_{i t}\right)$ (since the labor wedge depends on all factors affecting population and not just on $\ln \tilde{N}_{i t}\left(A_{i t}\right)$ ). Hence, we define $\tilde{\varepsilon}_{2}\left(g_{i t}, \tilde{\varepsilon}_{1}\left(g_{i t}, \gamma_{i t}\right)\right) \equiv \varepsilon_{2 i t}$.

We now use equation $(7)$ to decompose the effect from all three elements of $\left(A_{i t}, \gamma_{i}, g_{i t}\right)$. To do so, we estimate

$$
\ln \left(A R_{i t}\right)=\alpha_{3}+\beta_{3} \ln \widetilde{\tau_{i t}}+\beta_{4} \varepsilon_{1 i t}+\beta_{5} \varepsilon_{2 i t}+\varepsilon_{3 i t}
$$

using median rents for $A R_{i t}$. The model has clear predictions for $\beta_{3}, \beta_{4}$ and $\beta_{5}$. In particular, it implies $\beta_{3}>0$, since by equations (7) and (12) efficiency has a positive effect on population, which has a positive effect on the level of distortions and on average rents. This is the standard city size effect. The effects of $\gamma_{i t}$ and $g_{i t}$ are determined by the estimates of $\beta_{4}$ and $\beta_{5}$. Note that $\varepsilon_{1 i t}$ and $\varepsilon_{2 i t}$ depend on both $\gamma_{i t}$ and $g_{i t}$. However, since $\varepsilon_{2 i t}=\tilde{\varepsilon}_{2}\left(g_{i t}, \tilde{\varepsilon}_{1}\left(g_{i t}, \gamma_{i t}\right)\right)$ depends only on $\gamma_{i t}$ through $\varepsilon_{1 i t}$ and we are including $\varepsilon_{1 i t}$ directly in the regression, $\beta_{5}$ will capture only the effect of changes in $g_{i t}$ on land rents. So, $\beta_{5}$ captures the effect of $g_{i t}$ on frictions and therefore average rents. Higher distortions imply a higher $\tau_{i t}$. Hence, the model implies that higher $g_{i t}$, and therefore higher $\tau_{i t}$ and $\varepsilon_{2 i t}$, implies lower population and lower rents (see (12)). Thus $\beta_{5}$ should be negative. Similarly, since we are controlling for the effect of $g_{i t}$ by including $\varepsilon_{2 i t}, \beta_{4}$ will capture the effect of $\varepsilon_{1 i t}$ on land rents controlling for $g_{i t}$, which is the effect of $\gamma_{i t}$ on land rents, since $\varepsilon_{1 i t}=\tilde{\varepsilon}_{1}\left(g_{i t}, \gamma_{i t}\right)$. Hence, the model implies that $\beta_{4}$ should be positive by equations (7) and (12). Our model implies that rents are a non-linear function of $\left(A_{i t}, \gamma_{i}, g_{i t}\right)$. In contrast, equation (16) assumes that it is a linear function. Adding higher degree polynomials and interaction terms to this relationship can in principle be important. We do so in our empirical implementation below, though this does not affect results in any substantial way.

Note that we can then use equation (7) to relate average rents and population sizes. So we estimate equation (7) as

$$
\ln \left(N_{i t}\right)=\alpha_{4}+\beta_{6} \ln A R_{i t}+\varepsilon_{4 i t} .
$$


According to the model, in a circular city, $\beta_{6}=2>0$.

\subsection{Effects of Efficiency, Amenities and Frictions on City Size}

To bring the model to the data, we construct a new data set on U.S. metropolitan statistical areas (MSAs) for the period 2005-2008. Apart from output and rental prices, few ready-to-use data are available at the MSA level. We rely on a combination of proxies previously used in the literature and micro-data to come up with measures for the other relevant variables, such as consumption, hours worked, and capital. Appendix B.1 provides details on the construction of the data set. Computing the "labor wedge" and the "efficiency wedge" requires making assumptions on the values of some parameter values. Table 1 reports the parameter values we use and provides brief comments on the chosen values. Essentially, they make the model match key moments in the aggregate.

To implement the empirical exercise of the previous section, we pool the data for 2005-2008 and include time dummies in all regressions. One further difference is that we also include an interaction term $\varepsilon_{1 i t} \varepsilon_{2 i t}$ in equation (16), since we found it to be statistically highly significant. We denote the coefficient associated with this interaction term $\beta_{7}$. Standard errors for equations (16) and (15) are obtained by bootstrapping, since some of the regressors are estimated. ${ }^{4}$ The results are presented in Table 2.

\begin{tabular}{|c|c|l|}
\hline \multicolumn{2}{|c|}{ Table 1 } \\
\hline \hline Parameter & Value & Comments \\
\hline$\psi$ & 1.4841 & McGrattan and Prescott (2009) \\
$\theta$ & 0.3358 & McGrattan and Prescott (2009) \\
$r$ & 0.02 & Standard number in the literature \\
$\delta$ & 0.02 & Theory requires $\delta=r$ \\
\hline
\end{tabular}

As is clear from Table 2, all coefficients have the signs implied by the model and are highly significant. The estimation of equations (14), (15), (16), and (17) yields $R^{2}$ values of, respectively, $0.14,0.37,0.25$ and 0.18 . The model implies that in a circular city $\beta_{6}=2$. The value we find is close to two and we fail to reject the hypothesis that it is equal to two at the $5 \%$ level.

\footnotetext{
${ }^{4}$ Correcting the standard errors for clustering by MSA does not qualitatively change any of the results, except for $\beta_{3}$, which is no longer statistically significant.
} 


\begin{tabular}{|r|r|c|c|c|}
\hline \multicolumn{5}{|c|}{ Table 2} \\
\hline \hline$j$ & \multicolumn{1}{|c|}{$\beta_{j}$} & s.e. & p-value & Theoretical Prediction \\
\hline 1 & 2.0964 & 0.3727 & 0.000 & + \\
2 & 0.4127 & 0.0234 & 0.000 & + \\
3 & 0.1283 & 0.0461 & 0.005 & + \\
4 & 0.0959 & 0.0070 & 0.000 & + \\
5 & -0.2020 & 0.0420 & 0.000 & - \\
6 & 2.1400 & 0.1652 & 0.000 & 2 \\
7 & -0.1841 & 0.0437 & 0.000 & - \\
\hline \multicolumn{4}{|c|}{ Number of observations: 768} \\
\hline
\end{tabular}

These results allow us to reach several conclusions. First, highly efficient cities are more populated. This is consistent with numerous empirical studies in the literature. Second, efficient cities are more distorted. Frictions are larger as a result of these cities being larger. The frictions that result from more efficient cities being larger are positively related to median rents, since they are the result of the higher efficiency. Third, frictions that exceed the ones explained by efficiency have a negative effect on land rents and city size. Finally, cities that are larger due to amenities also exhibit larger median rents.

The model and the empirical exercise have allowed us to assess the impact of the three city characteristics (efficiency, excessive frictions, and amenities) on land rents and population size. It has also made the point that the general equilibrium effects are important. However, the empirical log-linear model that we have used does not inherit the entire structure of the model. For example, the derivatives in (12) need not be constant. It is therefore important to go beyond this simple empirical exercise to capture the full richness of the theoretical model. In the next section we propose a methodology to obtain the value of the three key city characteristics, and we use the model to perform counterfactual exercises. We show how the model can be made to account for all of the variation in city sizes if we identify amenities as a residual from the theory. 


\section{COUNTERFACTUAL EXERCISES}

\subsection{Methodology and Shock Identification}

The model provides a straightforward way of performing counterfactual exercises. Equation (11) implies that

$$
\begin{aligned}
& C_{1}\left(\bar{u}_{t}, \gamma_{i t}\right)-\log \left(C_{2}\left(A_{i t}, r_{t}\right)\right) \\
= & (1+\psi) \log \left(1-\left(\kappa \frac{2}{3} g_{i t}+\frac{\kappa}{C_{2}\left(A_{i t}, r_{t}\right)}\right)\left(\frac{N_{i t}}{\pi}\right)^{\frac{1}{2}}\right)-\psi \log \left(1-\kappa \frac{2}{3} g_{i t}\left(\frac{N_{i t}}{\pi}\right)^{\frac{1}{2}}\right) .
\end{aligned}
$$

If $g_{i t}$ and $\tau$ are small using the approximation $\log (1-x) \approx-x,{ }^{5}$ we obtain

$$
N_{i t}=\frac{\pi}{\kappa^{2}}\left(\frac{\log \left(C_{2}\left(A_{i t}, r_{t}\right)\right)-C_{1}\left(\bar{u}, \gamma_{i t}\right)}{\frac{(1+\psi)}{C_{2}\left(A_{i t}, r_{t}\right)}+\frac{2}{3} g_{i t}}\right)^{2}
$$

where

$$
\begin{aligned}
C_{1}\left(\bar{u}, \gamma_{i t}\right) & =\bar{u}_{t}+(1+\psi) \log (1+\psi)-\psi \log \psi-\gamma_{i t}, \\
C_{2}\left(A_{i t}, r_{t}\right) & =(1-\theta) \frac{A_{i t}^{\frac{1}{1-\theta}}}{\left(\frac{r_{t}}{\theta}\right)^{\frac{\theta}{1-\theta}}} .
\end{aligned}
$$

This solves $N_{i t}$ as a function of $\left(A_{i t}, \gamma_{i t}, g_{i t}\right)$. Note that the approximation results in exactly the same derivatives with respect to $\left(A_{i t}, \gamma_{i t}, g_{i t}\right)$. Furthermore, $\partial N_{i t} / \partial \bar{u}<0$, namely, a higher equilibrium utility (smaller total population) makes concentration of workers in a given city less likely since concentration implies congestion costs. ${ }^{6}$

We can use the equation above to calculate $N_{i t}$ given the values of $\left(A_{i t}, \gamma_{i t}, g_{i t}\right)$ and other parameter values. We can also use these expressions to run counterfactual exercises. In particular we can calculate counterfactual distributions of city sizes assuming that all cities have similar values of

\footnotetext{
${ }^{5}$ This approximation works best if $\tau_{i t}$ and $\kappa$ are small. In the exercise below the approximation error is likely very small.

${ }^{6}$ Throughout this section we calculate an agent's utility based on his labor and capital income but not on the income he obtains from land rents. Land is owned by absentee landlords and so rental income does not enter an agent's utility and does not affect his decision to move. We have calculated all of the results below if we use the alternative assumption that workers in a city own a diversified portfolio of land in the city and so obtain as income the average rents. The results under this assumption are essentially identical (utility differs only by less than 0.001) to the ones with absentee landlords, both in the case with and without externalities. The reason is that we are always normalizing the level of utility that reproduces the size distribution to $\bar{u}=10$ and only relative utilities matter to determine location decisions.
} 
any of the exogenous city characteristics $\left(A_{i t}, \gamma_{i t}, g_{i t}\right)$. Note that $\bar{u}_{t}$ has to be selected such that the resulting city sizes satisfy the labor market clearing condition (13).

In order to perform any of these exercises we first need to develop a strategy to calculate $\left(A_{i t}, \gamma_{i t}, g_{i t}\right)$ for each city. $A_{i t}$ can be calculated directly from available data since

$$
A_{i t}=\frac{y_{i t}}{k_{i t}^{\theta} h_{i t}^{1-\theta}}
$$

and we have data on $y_{i t}, h_{i t}$ and $k_{i t}$. This is what we did in the empirical implementation above. An alternative way of calculating the relevant productivity and skill term without using $k_{i t}$ (which is potentially poorly measured in the data) is to use the prediction of the model on capital allocation. In particular the model implies that $r_{t} k_{i t}=\theta y_{i t}$ and so

$$
k_{i t}=\frac{\theta y_{i t}}{r_{t}} .
$$

We can then let

$$
A_{i t}=\frac{y_{i t}^{1-\theta}}{\left(\frac{\theta}{r_{t}}\right)^{\theta} h_{i t}^{1-\theta}} .
$$

Equation (18) assumes that capital is determined in this way and so this method has the advantage of being theoretically more consistent (although it does not use the actual data on capital stocks). We have added capital in both waysand found the results to be similar. The correlation of the model-based capital stock measure and the empirical capital stock measure is 0.9. Therefore, we omit here the exercise with the theoretical levels of capital and focus on the one where we use the empirical measure of the capital stock.

Obtaining values for the other two city characteristics is more complicated. First note that equation (10) can be used to estimate $g_{i t}$. Based on this equation we can run the simple log-linear regression

$$
\ln \tau_{i t}-\frac{1}{2} \ln N_{i t}=\alpha_{5}+\varepsilon_{5 i t} .
$$

We use data for 2005-2008 and add time dummies. Equation (10) then implies that $\varepsilon_{5 i t}=\ln g_{i t}{ }^{7}$

We still have to obtain the value of $\gamma_{i t}$. There are a variety of ways to do this. The one that is most consistent with the theory is to use equation (18) and solve for the set of $\gamma_{i t}$ that makes the model match city sizes exactly, given some normalization of $\bar{u}$ (we set $\bar{u}=10$ ). We can then fix $\gamma_{i t}$ and perform counterfactual exercises. Of course, this exercise depends on the value of all

\footnotetext{
${ }^{7}$ Alternatively, we could run $\ln \tau_{i t}=\alpha_{5}+\beta_{8} \ln N_{i t}+\varepsilon_{5 i t}$. This is the same as (19) without restricting $\beta_{8}$ to be equal to $1 / 2$. Using efficiency as an instrument for population, we find $\beta_{8}=0.4$, similar to the 0.5 predicted by the theory.
} 
parameters in the model. As before, we use the parameters in Table 1, which match key moments in the aggregate. One important parameter in determining $\gamma_{i t}$ is $\kappa$, for which we have not assigned a value yet. To obtain a value for $\kappa$, notice that equation (9), together with regression (19), implies that

$$
\alpha_{5}=\ln \left(\frac{2}{3}\right)+\ln \kappa-\frac{1}{2} \ln \pi
$$

and so, given a value for $\alpha_{5}$ from regression (19), we can calculate $\kappa$. The estimation gives a value of $\kappa=0.002$. The time dummies we include are mostly not significant, and their values are so small that adding them would not change the value of $\kappa$.

\subsection{Counterfactuals}

We are now ready to perform a number of counterfactual exercises. After analyzing the effect of commuting costs, the main focus will be on exploring the relative importance of different characteristics (efficiency, amenities and excessive frictions) in determining the city size distribution. In particular, we are interested in understanding how changes in city characteristics affect city sizes, welfare and the reallocation of people.

Figure 1 shows the actual distribution of city sizes in the U.S. and counterfactual distributions of city sizes if we increase or decrease commuting costs $\kappa$, given the distribution of characteristics. The results are presented in the standard log population - log rank plots in which a Pareto distribution would be depicted as a line with slope equal to minus the Pareto coefficient. As is well known, the actual distribution is close to a Pareto distribution with coefficient one. By construction the model matches the actual distribution exactly for $\kappa=0.002$. In that case we normalize utility $\bar{u}=10 .^{8}$ In all counterfactual exercises we solve for the value of $\bar{u}$ for which the labor market clears, i.e., the sum of population across cities equals the actual total urban population. Note that percentage changes in utility are equivalent to percentage changes in consumption since we are using a logutility specification. Figure 1 shows that larger commuting costs make the largest cities smaller and the smaller cities larger, leading to a less dispersed distribution of city sizes. Doubling commuting costs decreases utility by about $6.1 \%$. Production moves away from the larger and most productive cities, which leads to welfare losses. Halving commuting costs increases dispersion and raises utility

\footnotetext{
${ }^{8}$ This normalization affects the size of the welfare changes due to the level taken by the amenity characteristics. On average we find that the share of utility coming from amenities is around $28 \%$. We have no evidence that this number is reasonable. However, it is easy to adjust the numbers to be consistent with any share of amenities in utility. For example, if the share of utility coming from amenities is set to zero, all our utility numbers from counterfactuals would need to be multiplied by $1 /(1-.28)=1.39$.
} 
by $3.1 \%$. Note that the smallest cities now become much smaller. The main advantage of some of these cities was their small size and their corresponding low level of congestion. As commuting costs decrease, this advantage becomes less important and their size decreases further.

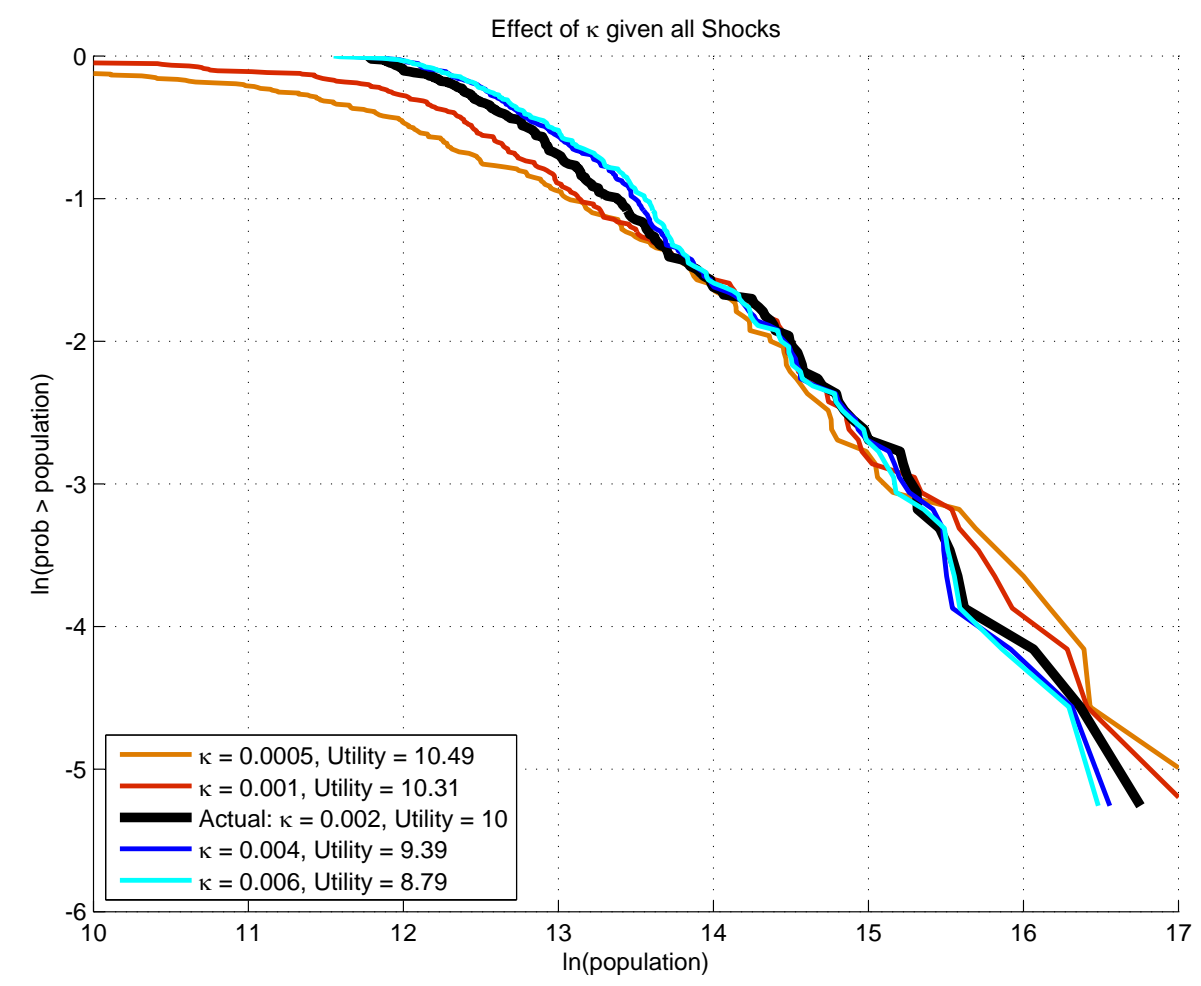

Figure 1: The City Size Distribution for Different Levels of Commuting Costs

Figure 2 shows three counterfactual exercises where we shut down each of the three city characteristics (efficiency, amenities, and excessive frictions), respectively. In all cases we eliminate a shock by setting its value to the population weighted average of the shock. We then calculate the utility level that clears the labor market, so total urban population is identical in all cases. Note that eliminating any of the shocks always leads to an increase in utility. Shocks create dispersion in the city size distribution and by equation (8) total commuting costs are convex. So utility in the model tends to increase if population is more evenly distributed in the 192 cities in our sample. If we eliminate all three shocks so that all sites are identical, welfare would increase by $1.54 \%$ and all cities would have a population of 1 million 68 thousand people. Of course, this increase in welfare does not constitute an upper bound on the importance of the shocks since the distribution of the shocks as well as their correlation matters for the final results. 

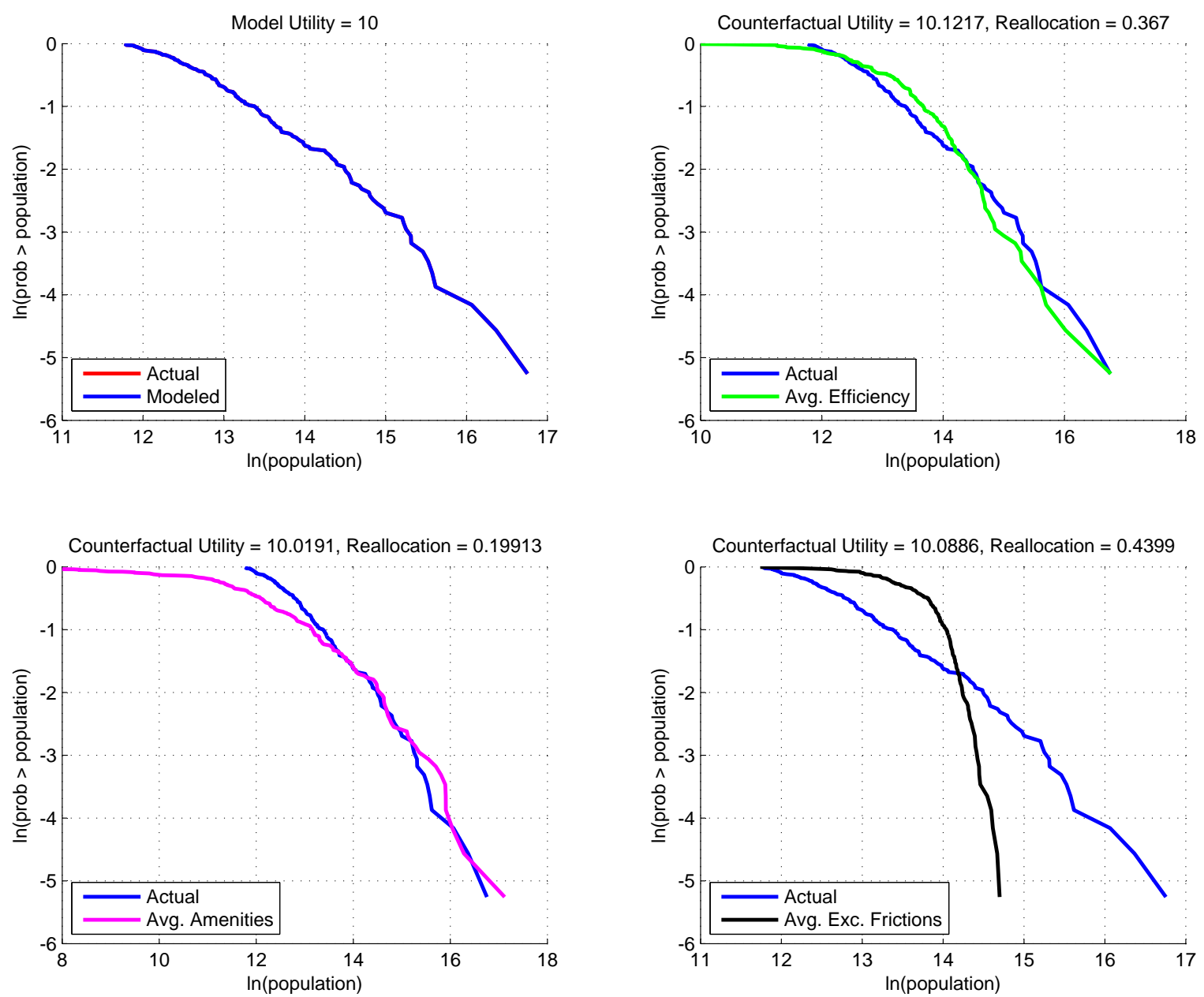

Figure 2: Counterfactuals Without One Shock, $\kappa=0.002$

The counterfactual exercises in Figure 2 show that eliminating differences in efficiency, amenities or excessive frictions has a small effect on utility. In all cases utility would increase by less than $1.5 \%$. The limited effect on utility is due to several reasons. The most obvious one is that population can reallocate across cities. But there are others. For example, the effect of a negative shock to productivity on utility is also mitigated by people working less, by lowering the cost of providing city infrastructure, and by the fact that utility does not only depend on production but also on amenities.

In spite of the small effect on utility, the effect on the size of individual cities is large. In the case of excessive frictions this is clear from Figure 2. Eliminating differences in excessive frictions tends 
to hurt larger cities and benefit smaller ones: New York and Los Angeles would lose up to $90 \%$ of their populations, whereas Santa Cruz and Trenton would gain, respectively, $145 \%$ and $326 \%{ }^{9}$ This suggests that larger cities have been successful, not just because of higher efficiency, but because they have been able to eliminate barriers and other frictions that hinder growth. However, there are notable exceptions: the population of Buffalo, a fairly large metropolitan area, would increase by $36 \%$ if differences in excessive frictions were eliminated.

Although maybe less obvious from Figure 2, equalizing efficiency or amenities also has a large effect on the size of individual cities. Larger cities would typically decline in size if they had average levels of efficiency. For example, Los Angeles would lose $29 \%$ of its population. The respective figures for New York and Chicago would be losses of $77 \%$ and $46 \%$. When equalizing amenities, the picture is more mixed. One pattern that emerges is that many East Coast cities would gain, whereas many West Coast cities would lose. For example, New York and Philadelphia would increase their populations by $44 \%$ and $39 \%$ if differences in amenities were eliminated, whereas Los Angeles and San Diego would lose $8 \%$ and $42 \%$ of their populations. One would expect that equalizing efficiency or amenities would tend to benefit smaller cities. This is indeed sometimes the case for example, the population of Fargo would increase by $183 \%$ if its amenities were equal to the average - but by bo means always. Some of the smaller cities decline because they lose their only comparative advantage. One such example is Santa Fe: if it had average amenities, it would lose $82 \%$ of its population. Intermediate-sized cities often benefit as they tend to experience a boost in productivity or amenities and are already attractive enough in terms of other characteristics. These cities also grow because of the reallocation of population from larger cities.

Appendix A shows figures and maps with the percentage changes in population for individual cities when we set one of the shocks to its weighted average. In terms of the geographic distribution of city characteristics, we find that most cities on the West Coast and in Florida would lose population if we eliminated amenity differences. This is consistent with Rappaport and Sachs (2003) and Rappaport (2007), who argue that the concentration of population in coastal areas with nice weather has to do increasingly with a quality of life effect. Central regions would tend to loose population if we eliminated efficiency differences as would most of the northeastern regions. Perhaps the sharpest geographical pattern emerges when we eliminate excessive frictions. Many of the cities in the Midwest and the Northeast, located in the "Rust Belt," would gain population if we equalized frictions across

\footnotetext{
${ }^{9}$ Whenever we mention city names, we are referring to the MSA. For example, Los Angeles refers to Los AngelesLong Beach-Santa Ana and New York refers to New York-Northern New Jersey-Long Island.
} 
cities. Examples include Rochester $(+37 \%)$, Syracuse $(+120 \%)$, Milwaukee $(+16 \%)$, AllentownBethlehem $(+14 \%)$, and Toledo $(+108 \%)$. This is an indication that governance problems, as well as other labor market frictions, like unions, may be important in these places.

The effect of the different shocks on the distribution of city sizes hides some of the implied population reallocation in these counterfactuals. That is, cities are changing ranking in the distribution even if the overall shape of the distribution does not always exhibit large changes, as in the case of amenities or efficiency. We can calculate reallocation following Davis and Haltiwanger (1992) by adding the number of new workers in expanding cities as a proportion of total population when we change from the actual distribution to the counterfactual. This measure of reallocation is $37 \%$ when we eliminate differences in TFP, $20 \%$ when we eliminate amenities, and $44 \%$ when we eliminate excessive frictions: large numbers given the modest welfare gains. As a benchmark, the same reallocation number for the U.S. economy over a 5 -year interval is around $2.1 \%$ (over the period 2003-2008).

Figure 3 shows the counterfactual distributions of city sizes when we shut down two of the three shocks. The distributions therefore show the heterogeneity in city sizes generated by a single shock or characteristic. Note that neither efficiency on its own nor amenities on their own can explain the relatively large sizes of both the smallest and the largest cities in the actual distribution. This is because some of these cities are attractive in terms of their other characteristics, making them larger than their efficiency or their amenities on their own would imply.

The level of commuting costs $\kappa$, which we have estimated to be equal to 0.002 , is a key parameter in determining the relative importance of each shock. The estimated value implies that agents spend about $1 \%$ of their wage income on commuting infrastructure. ${ }^{10}$ The larger $\kappa$, the smaller the relative importance of productivity shocks, since it becomes more costly to live in large productive cities and the people that live in them tend to work less since $\tau$ is larger. If we set $\kappa=0.006$, a threefold increase, the total reallocation if we equalize efficiency across locations drops from around $37 \%$ to $12 \%$, with a $0.7 \%$ increase in utility, half of the effect we had with $\kappa=0.002$. Reallocations decrease from $20 \%$ to $8.5 \%$ when cities have average amenities, and utility now goes up by $0.3 \%$, instead of by $0.2 \%$. The reallocation if we set excessive frictions to their average level remains essentially constant at $43 \%$. The changes in city sizes are highly correlated in the exercises with the two different values of $\kappa$.

\footnotetext{
${ }^{10}$ This number seems reasonable: estimates of government spending on transportation infrastructure as a share of GDP come up with figures around 1.5\% (Congressional Budget Office, 2007).
} 

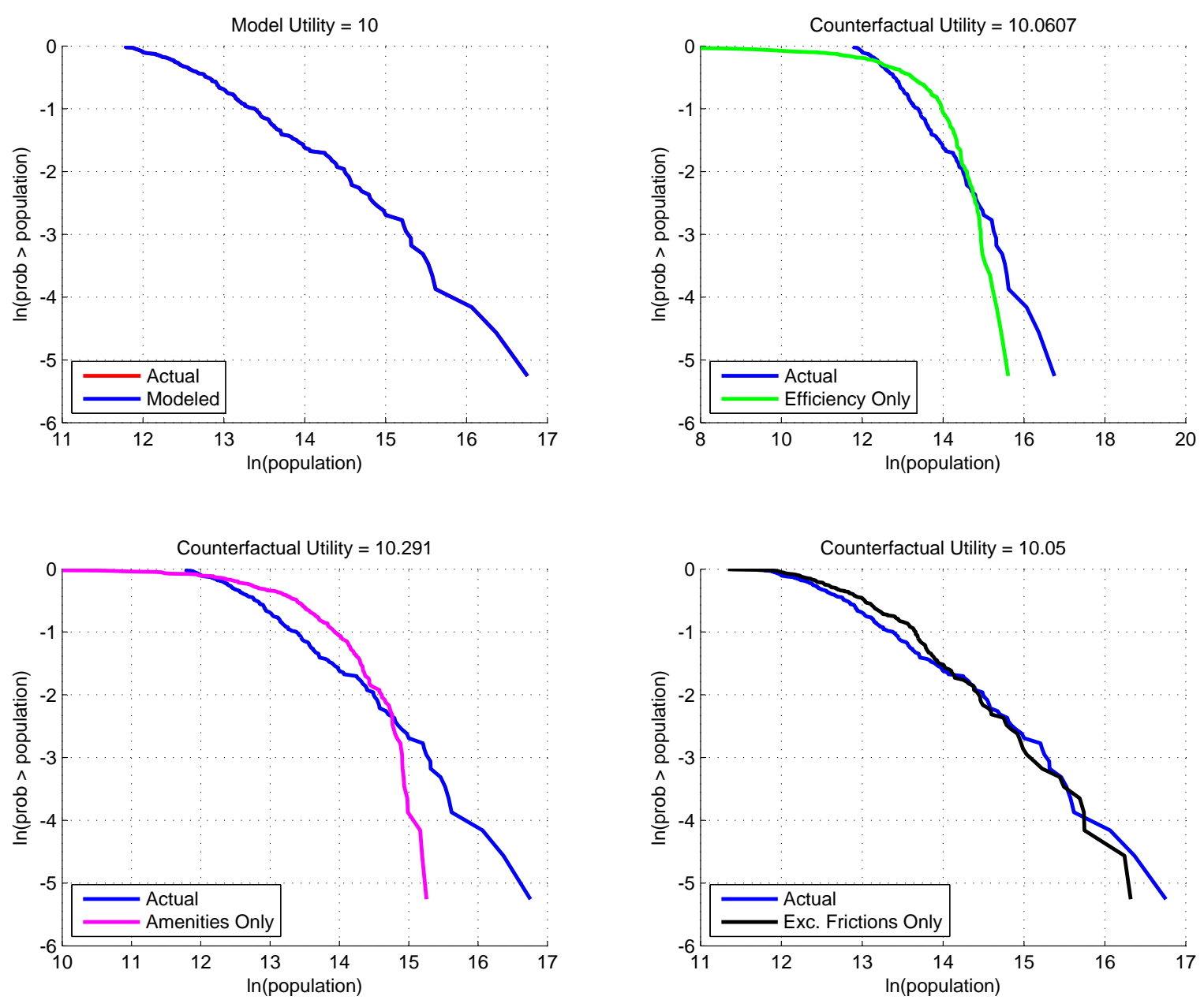

Figure 3: Counterfactuals with Only One Shock, $\kappa=0.002$

Figure 4 shows a counterfactual exercise when we set excessive frictions in all cities equal to the 10th, 50th or 90th percentile of the distribution of excessive frictions. First note that just eliminating the variation in excessive frictions across cities and setting them at the median decreases welfare by $50 \%$. The figure shows that reducing frictions in all cities to the 10 th percentile increases the dispersion of city sizes. Large cities gain the most in terms of population from the change, and many small cities exit. Utility increases by $4.2 \%$ relative to setting the level of frictions at the median. An opposite effect results from setting frictions to the 90th percentile, although the changes in the distribution are in general smaller. In this case utility declines by $5.5 \%$ relative to the case where excessive frictions are at the median. An increase in excessive frictions makes large 
cities particularly expensive since large cities use the commuting technology more intensively (as we discussed in Section 2.4). As a result, the economy produces in more uniformly sized cities and so fails to exploit the differences in efficiency and amenities across cities. This leads to a considerable change in utility.

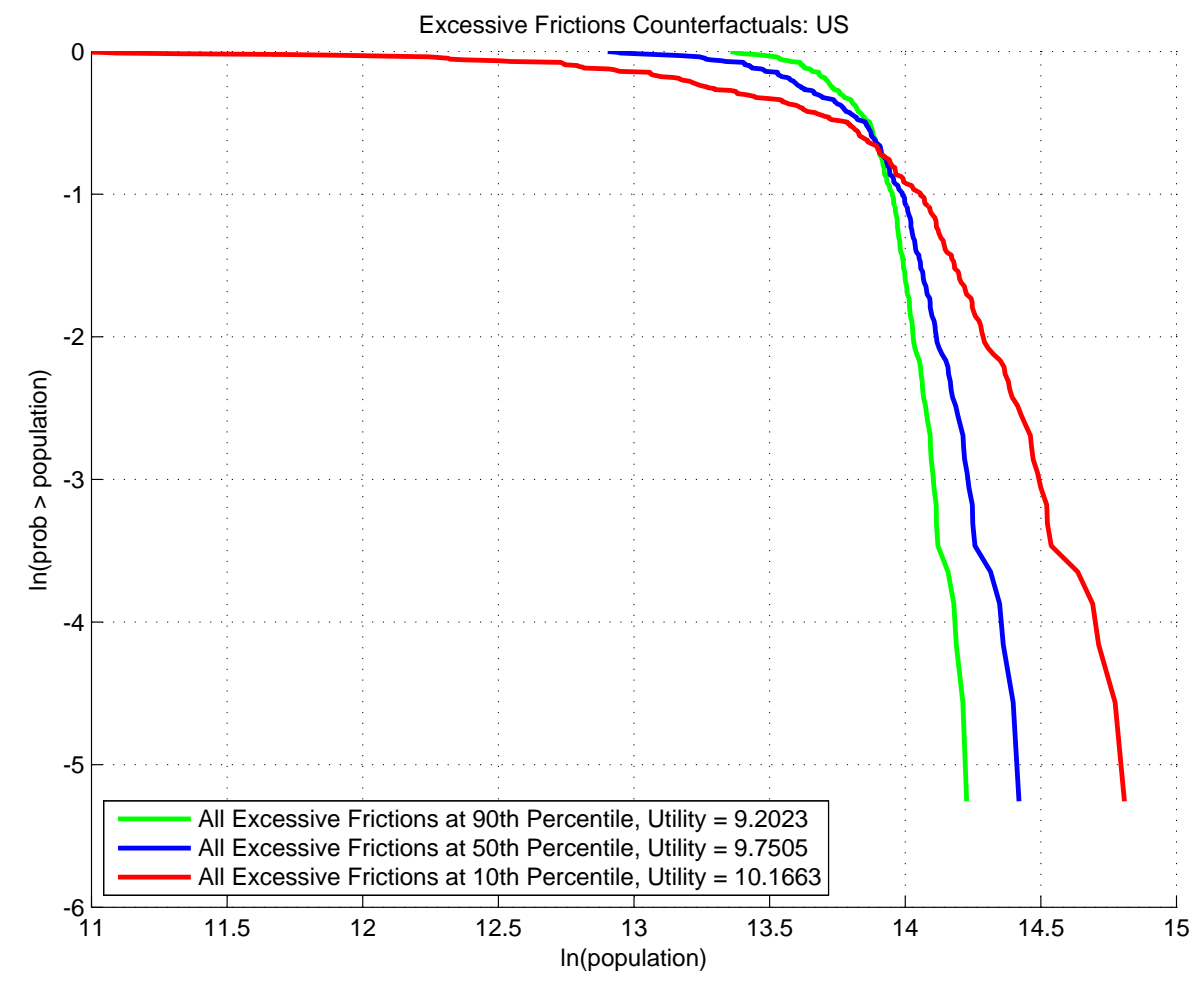

Figure 4: Changing the Level of Excessive Frictions

\subsection{Adding Production Externalities}

So far we have taken productivity in a particular city to be exogenously given. We have assumed that the efficiency of a particular site is not affected by the level of economic activity at that site. That is, so far, efficiency has explained agglomeration, but we have assumed away the reverse link by which agglomeration explains efficiency. Of course, a standard view in urban economics suggests that agglomeration is, at least in part, created by an increase in productivity coming from a rise in the number of people living in a given city. Including these agglomeration effects in our calculations has the potential to change our results, as this will have an endogenous effect on the size of a city. 
To incorporate these effects, we start with equation (18) but recognize that the term $A_{i t}$, which captures the efficiency of city $i$, is a function of the size of the city $N_{i t}$. In particular, we now let

$$
A_{i t}=\tilde{A}_{i t} N_{i t}^{\omega}
$$

That is, the level of productivity is now a function of an exogenous shock $\tilde{A}_{i t}$, and city size, $N_{i t}$, where the elasticity of the efficiency wedge with respect to population is given by $\omega$. Note that externalities operate within cities, and not across cities. We can then use the previous calculation of efficiency wedges in the data, using equation (2), and divide by population raised to $\omega$. The result is a set of new exogenous efficiency levels $\tilde{A}_{i t}$. We then substitute (20) in (18) and solve for the $\gamma_{i t}$ 's that yield the city's exact population levels. Excessive frictions are calculated as before. With all the city shocks in hand, we can now perform the same set of counterfactual exercises as before. Note that equation (18) now includes $N_{i t}$ in the productivity terms and so cannot be solved analytically. However, we can solve the system of non-linear equations numerically to obtain city sizes in the counterfactual exercises.

We still need to determine a suitable value for $\omega$. Of course, the estimation of equation (14) is not useful to determine $\omega$. In fact, this equation will fit exactly as in the data in our simulation of the actual economy. Instead, we rely on the literature, which suggests a fairly robust estimate of $\omega=0.02$ (see, among others, Carlino, Chatterjee and Hunt, 2006, and Combes, et. al, 2009). We therefore start with an initial value of 0.02 and perform some robustness checks. We also set $\kappa=0.002$ as estimated in the previous section.

Figure 5 presents the exercise with externalities in the case where we eliminate each shock individually. First note that when we eliminate one of the shocks, small cities tend to become a lot smaller and some no longer survive. We use a cutoff of $\log (8)$ to determine the cities that exit, which implies that cities become towns with about 3,000 people. The smallest MSA in our sample has a population of 129,000 . In particular, 15 cities exit when we equalize $\tilde{A}_{i t}$ across cities to its population weighted mean, 29 cities exit when we set amenities to their average value, and 6 cities exit with average excessive frictions. As in the case without externalities, these are cities that lose their only comparative advantage. With externalities, this loss gets compounded, leading some small cities to exit. As for the large cities, they tend to become a lot smaller when eliminating differences in excessive frictions, whereas their size does not change much when equalizing exogenous efficiency or amenity levels. This latter result can be explained by the smaller dispersion in exogenous efficiency or amenities. Comparing this case to the one without externalities, utility can increase 
or decrease. On the one hand, introducing externalities reduces the underlying differences across cities, implying utility gains because of convex commuting costs. On the other hand, differences in city characteristics allow cities to exploit external effects, implying utility losses when making cities more alike. As a result of these opposing forces, utility is virtually unchanged, relative to the case without externalities. Introducing externalities slightly increases the total reallocation required in the counterfactuals. Compared to the case without externalities, the total reallocation required in the counterfactual tends to go slightly up. This happens because the changes introduced by the elimination of these shocks get compounded through the effect of changes in population on efficiency.
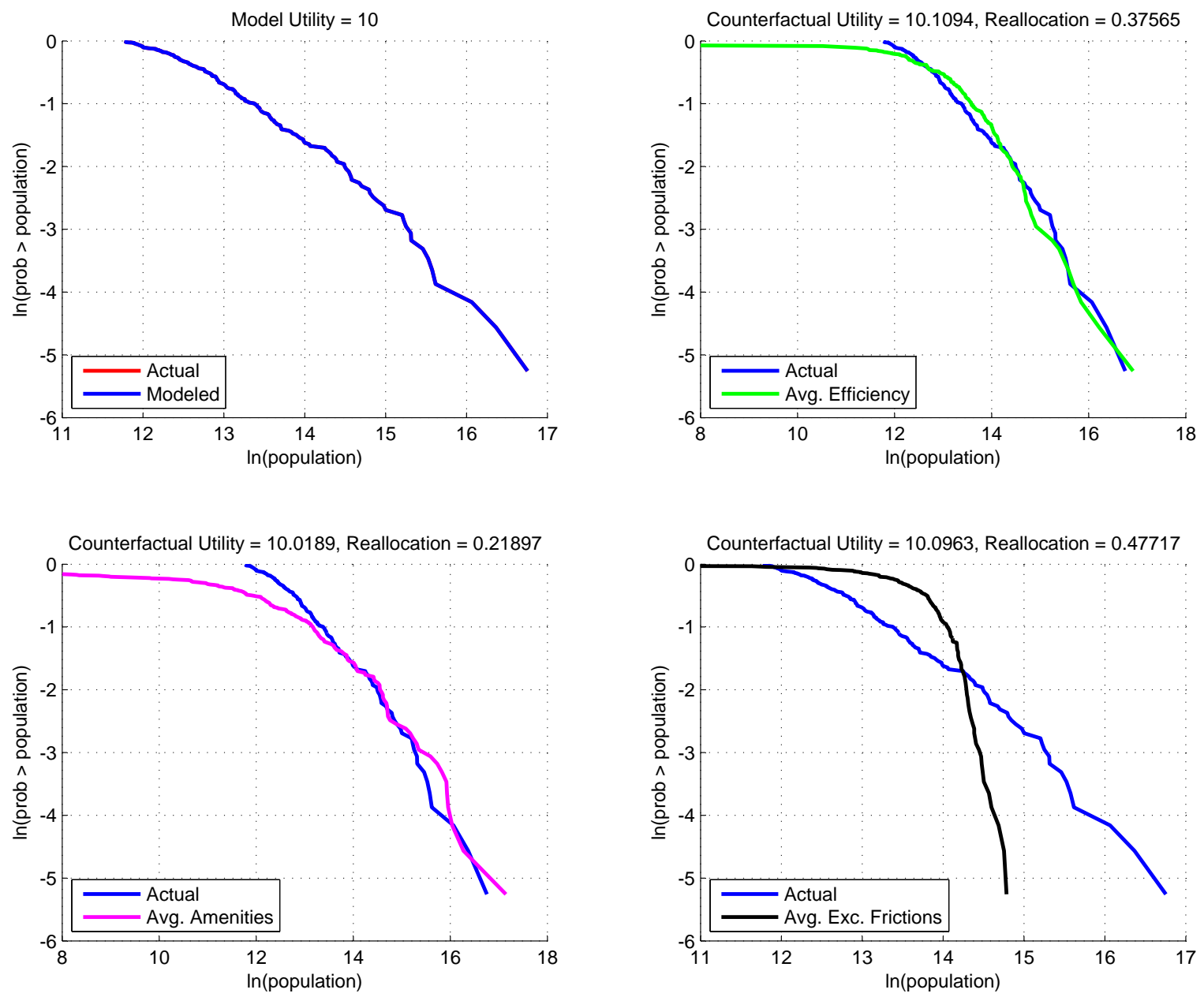

Figure 5: Counterfactuals Without One Shock and Externalities, $\kappa=0.002, \omega=0.02$

Figure 6 doubles the externality to $\omega=0.04$. This is closer to the estimate of 0.05 reported by 
Behrens, Duranton and Robert-Nicoud (2010). In general, the effects discussed before get exacerbated. Many more cities either exit or become very small. The results suggest that selection of cities in the presence of externalities can be important. Relative to the case without externalities, the increase in externalities does not significantly change the utility gains obtained if we equalize one of the city characteristics.
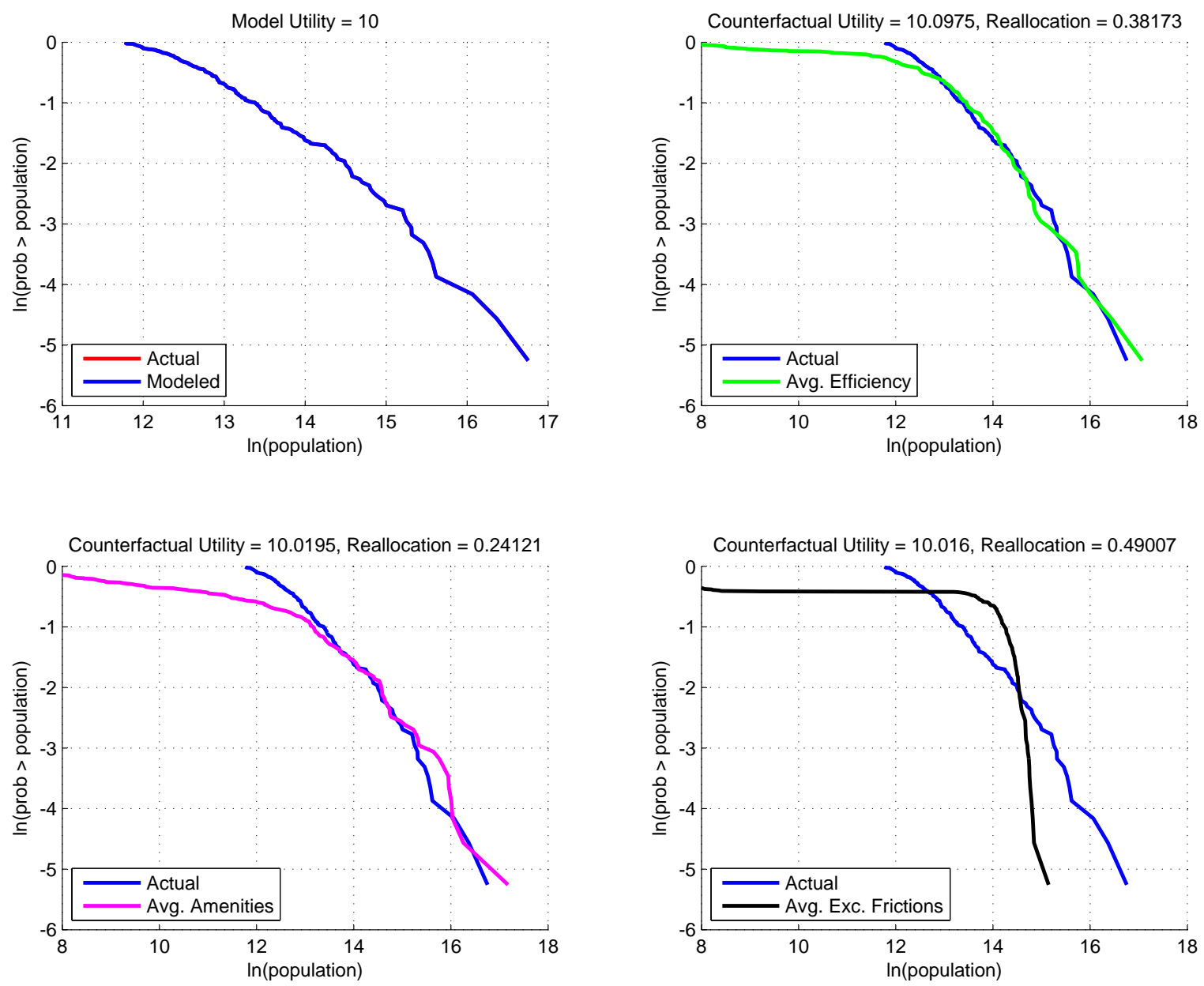

Figure 6: Counterfactuals Without One Shock and Externalities, $\kappa=0.002, \omega=0.04$

Adding externalities in production implies that the equilibrium allocation we compute is no longer efficient. In contrast with the exogenous productivity case, city planners could improve on the equilibrium allocation by subsidizing urban agglomeration. We can compute the optimal allocations in the case with production externalities by letting a representative firm internalize the external effect 
on productivity. Since the differences in welfare between the cases with and without externalities are so small, it is not surprising that the effect of these optimal urban policies is necessarily small as well. In fact, the gain in utility is only $0.58 \%$. Given that the informational requirements for these urban policies is extremely high, it is not clear that actual policy can achieve these small gains. Figure A10 in Appendix A compares the optimal and actual allocations.

We should also mention here that the exercise with externalities leads to the possibility of multiple equilibria in the size of cities. For many cities it will be the case that, given the equilibrium utility level, there is only one equilibrium size. But for other cities it will be the case that there are several possible equilibrium sizes. Our theory does not provide a way of selecting between these equilibria so we always present the one that requires less reallocation. That is, we always initialize the search for a solution of the size of a city at its actual size.

\subsection{Adding Externalities to Amenities}

We can also add externalities in the amenities a city provides. That is, we can let the utility from living in a particular city depend on the size of the city directly. People live in New York because living around a large number of people leads to a scale that provides them with a variety of goods and services, and interactions with people, which they enjoy. We have modeled the preference to live in a particular city through the amenity shocks $\gamma_{i t}$. So we can simply let

$$
\gamma_{i t}=\tilde{\gamma}_{i t} N_{i t}^{\zeta}
$$

where now $\tilde{\gamma}_{i t}$ is the exogenous amenity shock and $\zeta$ is the elasticity of amenities with respect to population size.

We repeat the exercise in Figure 5 but now we let $\zeta=0.02$ as well. Figure 7 shows the results. The results are qualitatively similar but now we observe that more cities become extremely small. That is, the selection mechanism we emphasized above becomes stronger. Equalizing city characteristics implies that externalities are not exploited as much. This effect is now bigger because of the two types of externalities. This explains why utility decreases relative to Figure 5 for the counterfactuals on both efficiency and excessive frictions. The opposite result for amenities reflects that some of the larger cities have worse amenities, so that eliminating amenity differences leads to a positive, though small, increase in utility. 

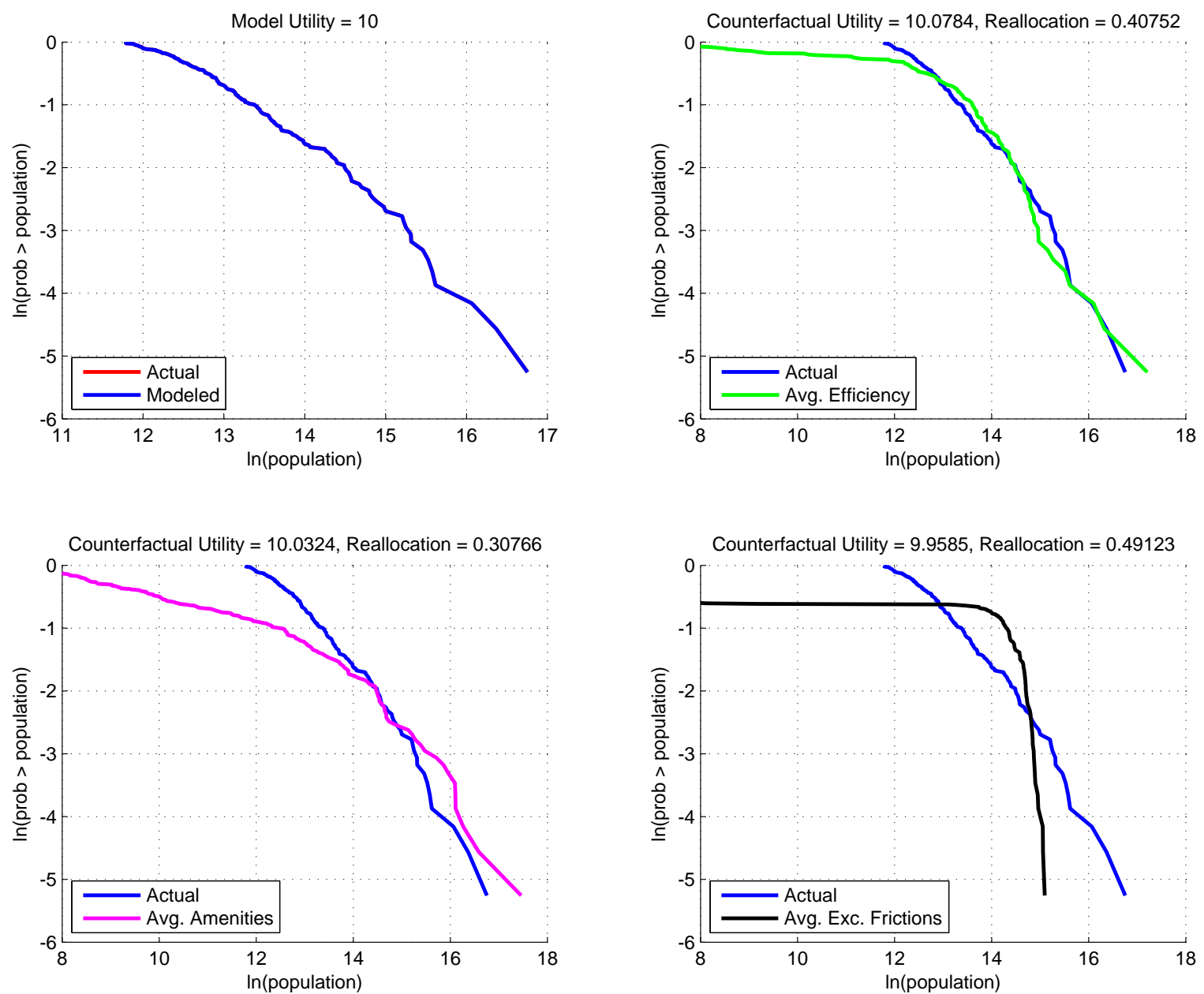

Figure 7: Counterfactuals Without One Shock and Externalities, $\kappa=0.001, \omega=0.02, \zeta=0.02$

Perhaps surprisingly, the effects on utility of eliminating the differences in any of our three characteristics are extremely small in magnitude, even though the implied reallocation of agents is, again, fairly large. Eliminating efficiency differences increases utility by $0.8 \%$ but implies that $41 \%$ of agents reallocate. The same reallocation statistics when we eliminate amenity differences is $31 \%$ and $49 \%$ for excessive frictions. Most of the reallocation comes from the extensive margin. Many cities become extremely small: the city selection effect. Once again, by equalizing a given characteristic, some small cities lose their only comparative advantage. This loss is compounded by the existence of externalities, so that quite a few smaller cities become so small that they exit. However, the reallocation has small effects on agents' utility, since even though small cities do not experience the benefits of large externalities, they are not distorted through taxes since city infrastructure is 
cheap. The slope of the envelope of the value of living in different cities is extremely flat, so agents switching locations leads to small utility gains.

City selection can be most easily understood by studying what happens if we eliminate differences in all three city characteristics. In this case the urban structure has 117 cities with 1,752,525 agents and the other 75 cities essentially disappear and preserve a population of only 538 agents in each of them. Without any city characteristics, but with externalities, there are two city sizes that give agents identical utility levels and the number of cities in each size is determined by the market clearing condition so that all agents are housed in some city. So there is an equilibrium that specifies the number of cities of each type. The utility level in this case is 9.991. Thus, eliminating all shocks yields small losses to agents as most agents live in smaller cities and some live in very small towns that have no congestion or infrastructure costs but also no gains from agglomeration. Note again that since there are no shocks, we know that in this case there may be multiple equilibria. As before, in all cases we compute the equilibrium with minimal reallocation of agents across cities, which also yields a level of utility closest to the one in the actual distribution, namely, 10.

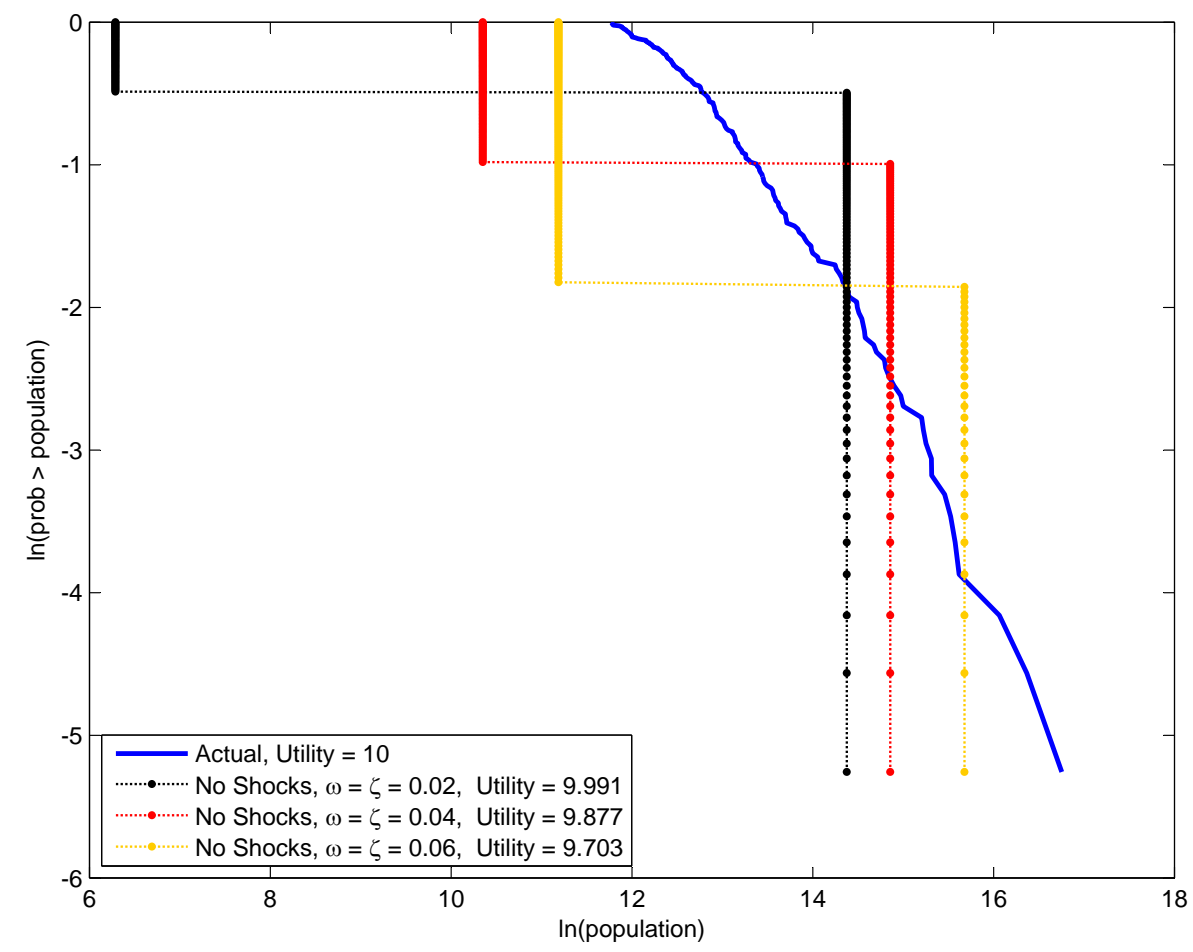

Figure 8: Counterfactuals Without Shocks, $\kappa=0.002$ 
Figure 8 shows counterfactuals without shocks for different elasticities of city efficiency and amenities to population size. Clearly, as we increase the elasticity, and therefore the externality, we still have two sizes of cities, but the larger the externality, the larger and fewer the larger cities. So larger externalities make the larger and smaller cities larger and increase the number of small cities. Furthermore, the larger the externality, the lower the utility in the counterfactual without shocks. When externalities are large, differences across cities create agglomeration and result in benefits. Eliminating them yields lower utility.

\section{THE EFFECT OF EFFICIENCY AND AMENITY SHOCKS}

In this section we study the effect on welfare and labor reallocation of shocks to efficiency and amenities. The model we have proposed to analyze the urban hierarchy has no dynamics, since all factors reallocate in a frictionless manner across cities. There are some dynamics in the process of accumulating capital but we neglect those and focus on the steady state (since these dynamics are just aggregate and have been well studied in the macroeconomics literature).

The purpose here is to understand what the magnitudes of welfare losses are if the economy is hit by, say, a $20 \%$ negative efficiency shock. We consider a proportional decrease in productivity in all cities and a random uniformly distributed proportional shock ${ }^{11}$ that amounts to different declines in average productivity. Figure 9 shows the effect on utility (top panel) and worker reallocation (bottom panel). In this exercise we calculate utility including the gains from changes in land rents in order to account exactly for an agent's welfare (although this has a negligible impact).

As can be seen in Figure 9, if every city experiences a proportional reduction in efficiency, the urban hierarchy remains the same, so there is no reallocation of agents. In this case, the value of commuting $\operatorname{costs} \kappa$ does not affect the slope of the welfare losses: the negative effect on welfare of an increase in the shock is independent of $\kappa \cdot{ }^{12}$ The most important observation is that although shocks reduce utility, they do so much less than proportionally. The reason is threefold. First, agents can adjust their leisure as a result of the shock as well as the amount of capital. Second, agents obtain utility out of the amenities in the city and so consumption of goods is only one of the elements that determines an agent's utility. The utility that agents obtain from city amenities amounts, on

\footnotetext{
${ }^{11}$ We use a proportional shock to productivity of the form $s_{i t}=0.5+x_{i t}$, where $x_{i t} \sim U(0,1)$, and $s_{i t}$ is multiplied by 1 minus the size of the average shock we analyze.

${ }^{12}$ Of course, an increase in $\kappa$ leads to lower utility as more output is lost on commuting, but this does not show up in the graphs, since in all cases the utility has been normalized to 10 when the shock is zero.
} 
average, to around $28 \%$ of an agent's utility. Third, commuting costs and the distortions created to build the related public infrastructure go down with productivity and wages.
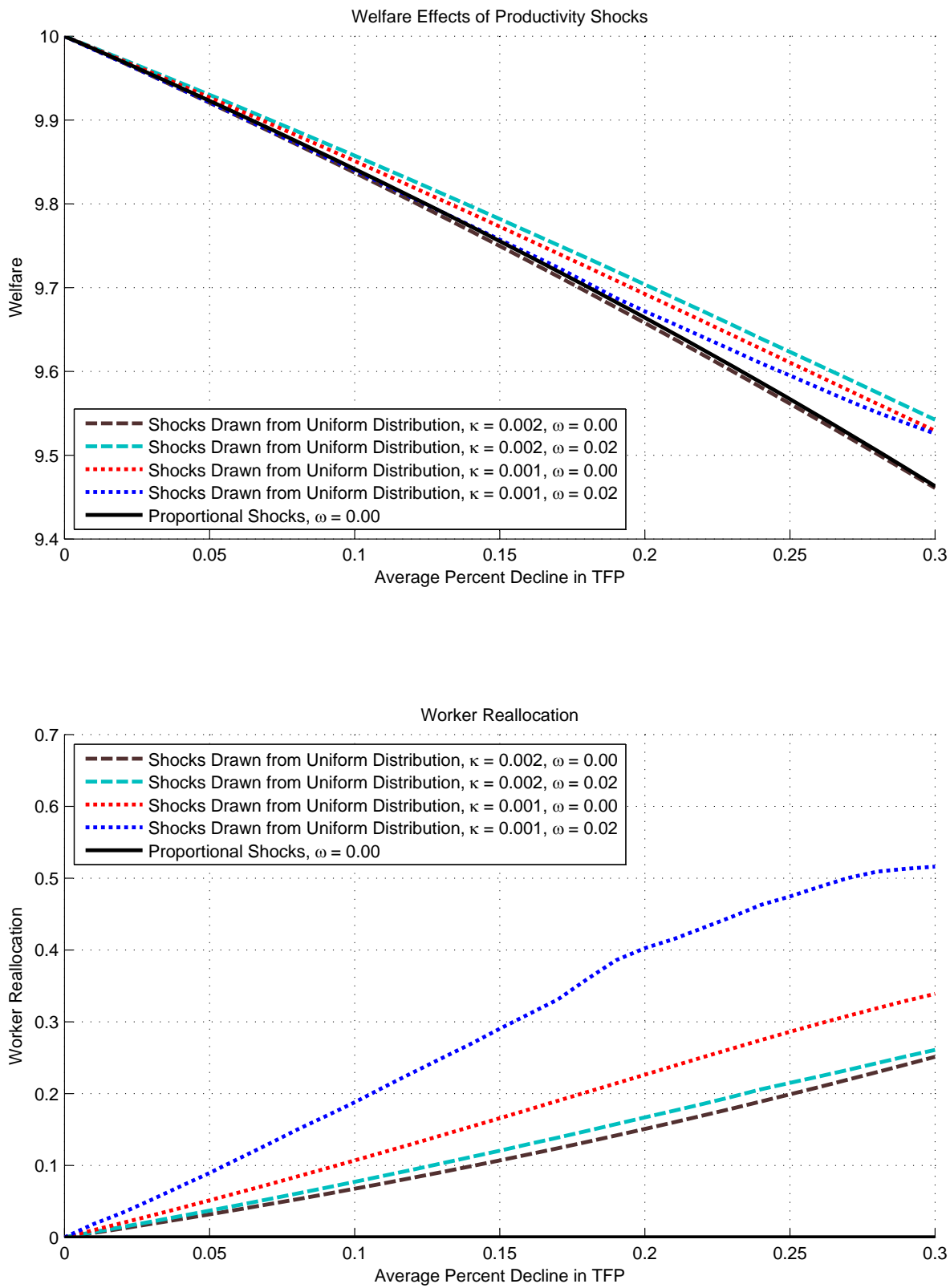

Figure 9: The Effect of Negative Productivity Shocks

If cities receive random, but on average negative, TFP shocks, the welfare costs are slightly smaller, since agents can relocate to the cities that received relatively good shocks. If we reduce commuting 
costs by half to $\kappa=0.001$, the overall utility loss is slightly lower, as reallocation tends to go from smaller to larger cities. So the utility loss for a shock to productivity of $30 \%$ on average goes from $5.3 \%$ with $\kappa=0.002$ to $4.7 \%$ with $\kappa=0.001$. The impact of higher commuting costs on reallocation is more substantial, since higher congestion costs slow down the move toward larger cities. Overall, random shocks create significantly more reallocation, but the welfare implications are minor. The fact that all curves in the top panel are close to each other suggests that changes in commuting costs, as well as including externalities in production, have small effects on the welfare consequences of these shocks. The figure also shows that in all these cases, the urban structure, and in particular migration between cities, mitigates the impact of productivity shocks. It is also clear from the graph that the benefits from the implied population reallocations are extremely small. In general, adding externalities leads to more reallocation since many cities disappear. However, the welfare impact of these selection effects is, again, very small.

We can also study the effect of amenity shocks. Figure 10 presents the results of a proportional (amenities change in all cities by the same proportion) and a random uniformly distributed proportional shock (the average of the shock amounts to a given proportion). When the amenity shock is proportional, there is reallocation of people across cities since the overall attractiveness of a city is also formed by productivity and the effectiveness in providing urban infrastructure.

The welfare losses from these shocks are larger than in the case of productivity. Since we know that amenities amount to around $28 \%$ of average utility, we would expect welfare to go down by slightly more than one quarter of the original shock. The calculation is not exact since reallocation and other adjustments change the actual welfare losses, but it provides a helpful benchmark. In fact, the accuracy of this back-of-the-envelope calculation (welfare goes down by around 6 to $8 \%$, depending on the case) shows that the benefits from reallocation are again very small. Adding externalities in this case decreases welfare and increases reallocation. In the case of amenity shocks, an increase in the value of $\kappa$ has a greater negative effect on welfare, compared to the case of productivity shocks. This happens because amenity shocks imply more reallocation than productivity shocks. The conclusion is that shocks that yield on average a $30 \%$ reduction in amenities reduce welfare by around $7 \%$. 

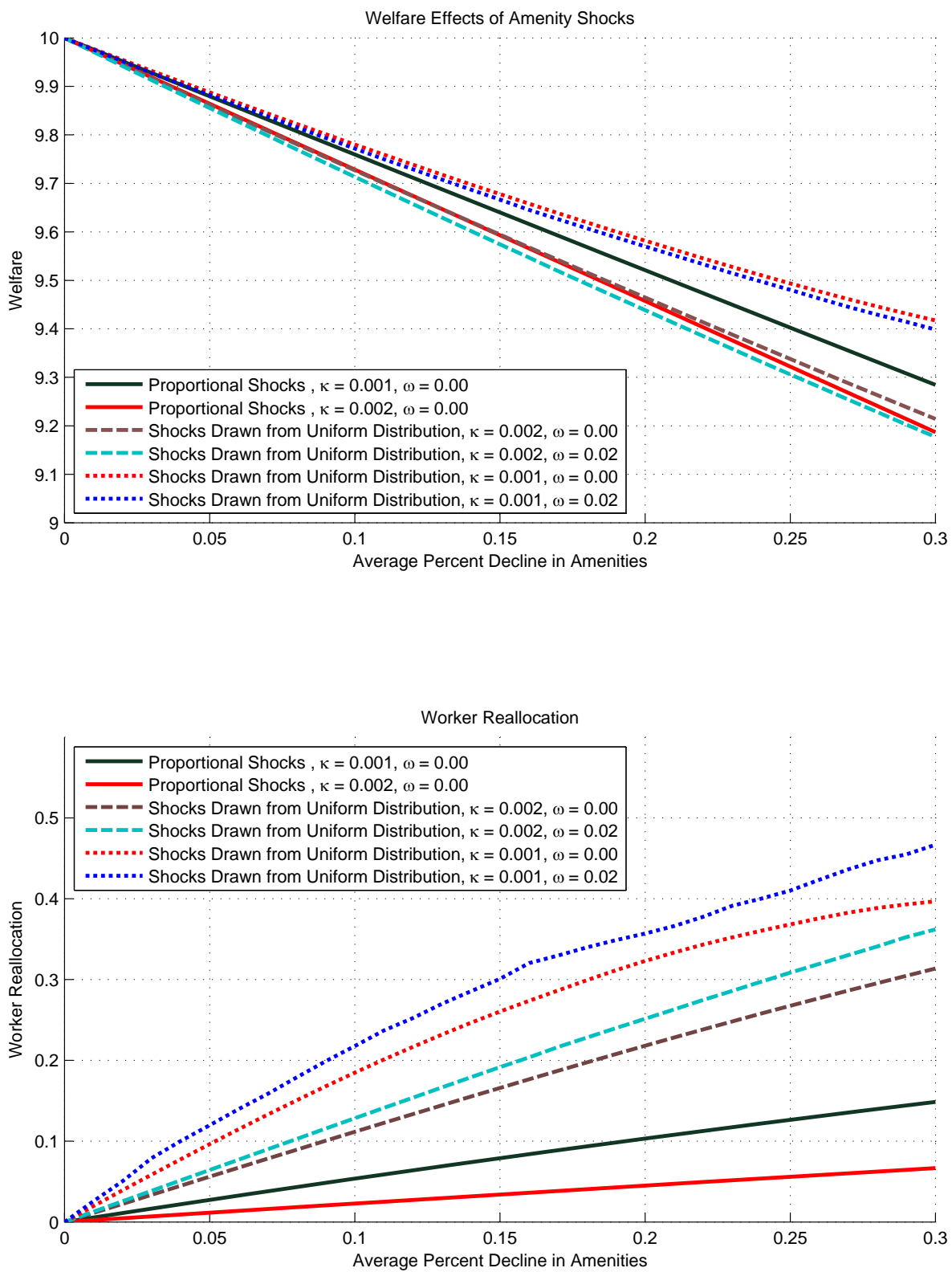

Figure 10: The Effect of Negative Amenity Shocks

\section{CHINA}

The most important finding so far is that eliminating differences in efficiency, amenities or excessive frictions leads to large reallocations of people but to small welfare effects. It is unclear whether this 
conclusion is general, inherent to the model, or specific to the U.S. To address this question, we carry out a similar analysis for the case of China.

The details of the database we built for 212 Chinese cities for 2005 are given in Appendix B.2. The data we need are the same as for the U.S. and come from China City Statistics and from the $20051 \%$ Population Survey. Two further comments are in order. First, in China a prefecture-level city is an administrative division below a province and above a county. Prefecture-level cities cover the entire Chinese geography. They include both the urban parts and the rural hinterlands and are therefore not the same as cities in the U.S. Luckily, the data tend to provide separate information for the urban parts of cities (referred to as districts under prefecture-level cities or also as city proper). In our database we focus on those districts under prefecture-level cities, as these are the closest equivalents to MSAs in the U.S. Second, when using Chinese data, the issue of their quality inevitably comes up. City-level data tend to be collected by local statistical agencies and are commonly perceived to be of very high quality. ${ }^{13}$

In order to estimate efficiency, amenities and excessive frictions, we need to use parameter values specific to the Chinese economy. We set the capital share of income $\theta=0.5221$ and the real interest rate $r=0.2008$ (Bai et al., 2006). Consistent with our analysis of the U.S., we use the same approach as McGrattan and Prescott (2009) to estimate $\psi$ for China and find a value of 1.5247. We use a value of $\kappa=0.001$, which we find using the same methodology as in the U.S. case. Once again, Appendix B.2 provides more details. In any case, the exact values for the different parameters play a limited role. When using the U.S. parameter values for our exercise on China, the main findings are largely unchanged. The reason is that modifying any of the parameter values has a limited impact on the distribution of the relevant variables across cities. We set externalities equal to zero in all exercises with Chinese data.

For the purpose of comparison, we run the same benchmark counterfactual exercise as in the case of the U.S. This exercise shuts down in turn each of the three shocks (efficiency, amenities and excessive frictions). Results for China are shown in Figure 11 and should be compared to the results for the U.S. in Figure 2. ${ }^{14}$ The most striking difference with the U.S. is that the welfare effects in China are now an order of magnitude larger. If all Chinese cities had the same level of efficiency,

\footnotetext{
${ }^{13}$ See $\mathrm{Au}$ and Henderson (2006) for a further discussion of the quality of city-level data in China.

${ }^{14}$ There is one difference with the exercise we perform for the U.S. When shutting down a shock, we set it equal to the median, rather than the weighted mean, of all cities. This change underestimates the difference between China and the U.S. We do this differently because the weighted mean of Chinese city TFP would make cities so productive that an equilibrium with the same number of cities does not exist.
} 
welfare would increase by $47 \%$, and if all had the same level of amenities, welfare would increase by 13\%. The corresponding figures for the U.S. are $1.2 \%$ and $0.2 \%{ }^{15}$ Another way of understanding the difference in magnitude is that in order to maintain utility at its original level, it would be enough to give all Chinese cities an efficiency level corresponding to the lowest 27th percentile.
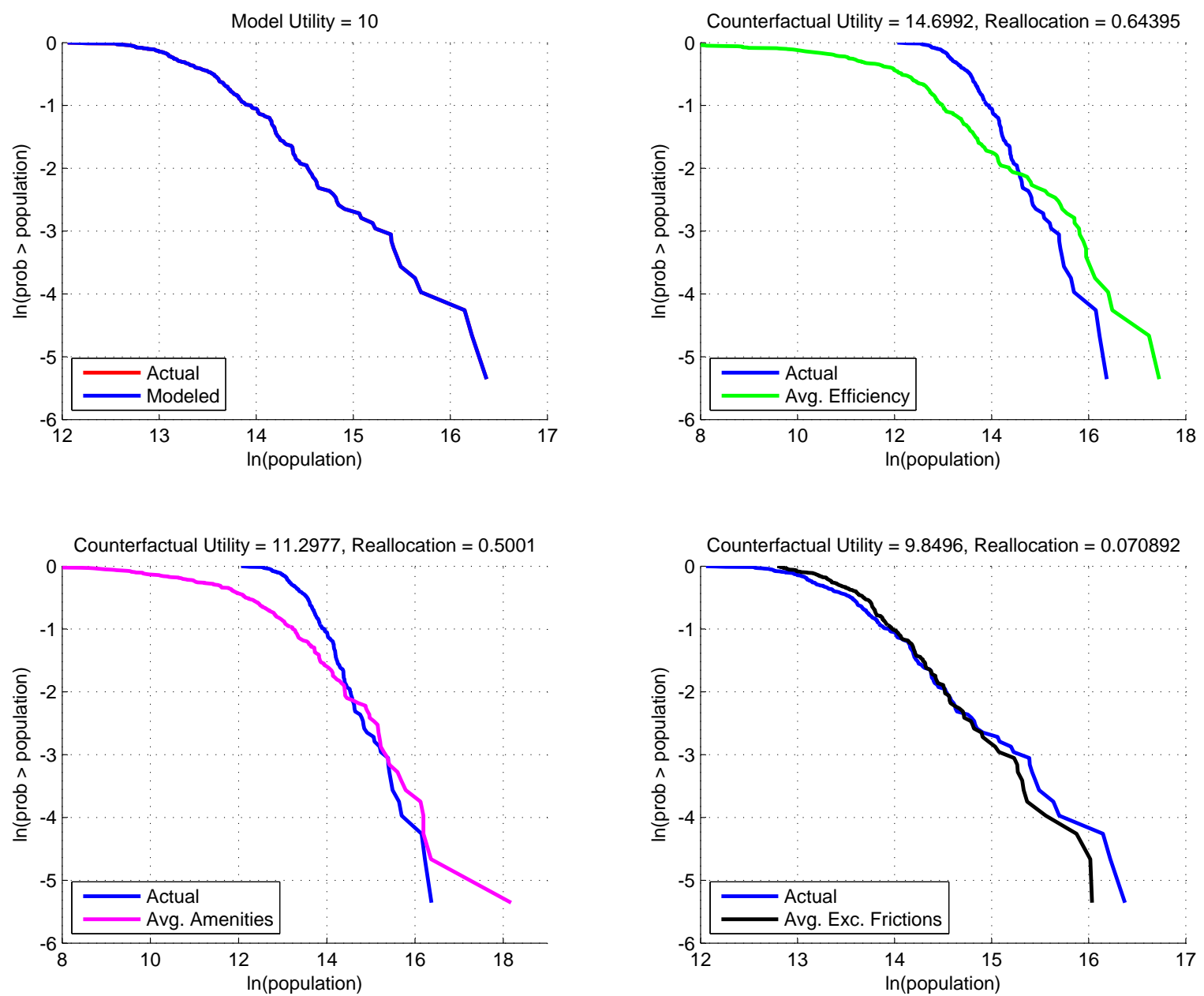

Figure 11: China Counterfactuals Without One Shock

Note also that the total reallocation of population is similar to that in the U.S. even though the welfare gains are much larger. Some examples can be informative: both Beijing and Shanghai would lose about $31 \%$ of their population if we equalize productivity. In contrast, if we equalize

\footnotetext{
${ }^{15}$ Shocks in China were set equal to their median. Given that the median is below the mean, the figures for China should be interpreted as lower bounds.
} 
amenities, Beijing would lose $10 \%$ of its population while Shanghai would lose only 1\%. Equalizing excessive frictions also leads to large effects in some cities. For example, Shenzhen, one of the "special economic zone" cities would lose $71 \%$ of its population if we equalize excessive frictions.

When equalizing efficiency or amenities across Chinese cities, the size distribution becomes more dispersed, with the larger cities being larger and the smaller cities being smaller. In contrast, in the U.S. the larger cities become smaller if we shut down efficiency differences, whereas the effect is less clear when we turn off amenity differences. Large cities in China are in general more efficient, but quite a few have worse amenities than smaller cities. If all cities had the same amenities, some of the larger ones would become more attractive, making them even larger. Given that larger cities tend to be more efficient, it is not immediately obvious why equalizing efficiency levels skews the distribution toward larger cities. What happens here is that some of the intermediate-sized cities, with higher amenities than the largest cities, now get higher levels of efficiency, and end up becoming very large cities. In other words, when equalizing amenities, the already larger cities become even larger, whereas when equalizing efficiency, some intermediate-sized cities become much larger. This is consistent with population reallocation being lower when equalizing amenities (50\%) than when equalizing efficiency $(64 \%)$. Another potential explanation is that large cities, even though they are better at everything, are artificially kept small by migration restrictions. The relatively small population combined with large efficiency would lead our model to estimate low amenities and high frictions for these cities, leading to the mechanism described above. This would be consistent with the finding of $\mathrm{Au}$ and Henderson (2006) that Chinese cities are too small.

We have not yet discussed the effect of equalizing excessive frictions across cities. When setting excessive frictions equal to the median, we find that welfare declines by $1.5 \%$. The relatively small effect does not imply that excessive frictions are small in China. To see this, Figure 12 shows the impact on welfare and the city size distribution of setting excessive frictions to the 90th and the 10th percentile of the distribution of excessive frictions, a similar exercise to the one we presented for the U.S. in Figure 4. If all cities had the excessive frictions of the 90th percentile, welfare would drop by $5.8 \%$, and the larger cities would become smaller. Likewise, if all cities had the excessive frictions of the 10th percentile, welfare would increase by $3.5 \%$, and the larger cities would become larger. Overall, the figure indicates that the changes in the size distribution of cities are smaller than in the U.S., but the utility implications are similar in magnitude. In China, excessive frictions are less important in explaining the dispersion in the size distribution of cities, but their average level is as high as in the U.S. 


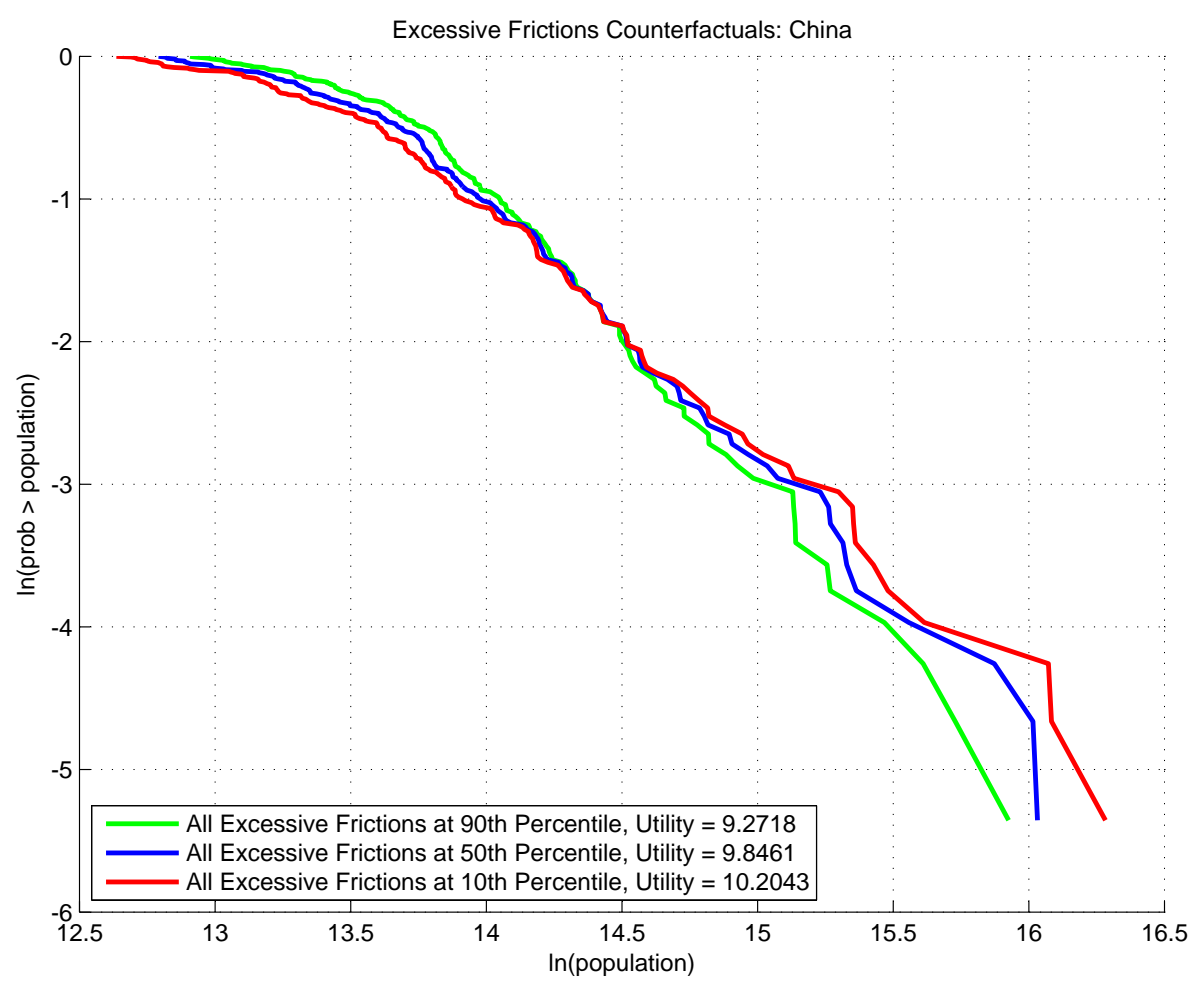

Figure 12: Changing Excessive Frictions in China

\section{CONCLUSION}

In this paper we have decomposed the size distribution of cities into three main characteristics: efficiency, amenities, and excessive frictions. We find that each one of these components is important. Eliminating differences in any of them would imply large reallocations of people. In the U.S. the welfare gains or losses associated with particular distributions of these characteristics are very small. Eliminating any differences in characteristics across cities yields welfare gains of at most $2 \%$. Note that the actual population movements required can be larger than $40 \%$, so any small reallocation cost would turn these gains into losses. We also include externalities in both productivity and amenities. The welfare effects associated with eliminating particular characteristics of cities are even smaller in these cases, although we find a strong selection effect in the counterfactual distributions. Namely, many cities exit or become extremely small.

The negligible effect in terms of welfare are not inherent to the model. Applying the same method- 
ology to Chinese cities reveals welfare effects that are an order of magnitude higher. Of course, the impact on welfare could be further enhanced if one were to add distributional effects in a model with heterogeneous agents. Also, if the number of cities were smaller, reallocating by moving to similar cities becomes more difficult, leading to larger welfare effects.

The results for the U.S. also suggest that a potential lack of mobility across locations (that could be caused, for example, by agents being "underwater" with their mortgages) can at most involve limited effects on welfare. We find that a $20 \%$ reduction in productivity leads to a reduction in welfare of between $3 \%$ and $4 \%$, while a reduction of $20 \%$ in amenities leads to a reduction in welfare of between $4 \%$ and $6 \%$. These reductions in welfare change only by a small fraction of a percent if we use idiosyncratic city shocks that average to the same decline. These results suggest that the implied reallocation of agents that results from idiosyncratic shocks has small welfare effects in the U.S.

More generally, we have provided a simple methodology to study the determinants of the size distribution of cities. This methodology can be useful in comparing urban systems across countries. We have illustrated this by also analyzing the case of China. The data requirements to do the exercise are not extreme, and it could shed light on the sources of differences in urban systems across countries. Such a comparison will be informative about the effectiveness and welfare effects of different policies aimed at making the location of agents across cities more efficient. 


\section{REFERENCES}

[1] Albouy, D., 2008. "Are Big Cities Really Bad Places to Live? Improving Quality-of-Life Estimates across Cities," NBER Working Papers 14472.

[2] Albouy, D., 2009. "What Are Cities Worth? Land Rents, Local Productivity, and the Capitalization of Amenity Values," NBER Working Papers 14981.

[3] Asdrubali, P., Sorensen, B.E. and Yosha, O., 1996. "Channels of Interstate Risk Sharing: United States 1963-1990," Quarterly Journal of Economics, 111, 1081-1110.

[4] Au, C.-C. and Henderson, J.V., 2006. "Are Chinese Cities Too Small?," Review of Economic Studies, $73,549-576$.

[5] Bai, C.-E., Hsieh, C.-T. and Qian, Y., 2006. "The Return to Capital in China," Brookings Papers on Economic Activity, 37, 61-102.

[6] Behrens, K., Duranton, G. and Robert-Nicoud, F., 2010. "Productive Cities: Sorting, Selection, and Agglomeration," unpublished manuscript.

[7] Behrens, K., Mion, G., Murata, Y., and Südekum, J., 2010. "Agglomeration and Firm Selection," unpublished manuscript.

[8] Bleakley, H. and Lin J., 2010. "Portage: Path Dependence and Increasing Returns in U.S. History," NBER Working Papers 16314.

[9] Carlino, G., Chatterjee, S., and Hunt, R., 2006. "Urban Density and the Rate of Invention," Working Paper 06-14, Federal Reserve Bank of Philadelphia.

[10] Chari, V. V., Kehoe, P., McGrattan, E., 2007. "Business Cycle Accounting," Econometrica, 75, 781-836.

[11] Combes, P, Duranton, G., Gobillon, L., Puga, Diego and Roux, S., 2009. "The Productivity Advantages of Large Cities: Distinguishing Agglomeration from Firm Selection," CEPR Discussion Papers 7191.

[12] Congressional Budget Office, 2007. "Trends in Public Spending on Transportation and Water Infrastructure, 1956 to 2004," August. 
[13] Córdoba, Juan Carlos, 2008. "On the Distribution of City Sizes," Journal of Urban Economics, 63, 177-197.

[14] Davis, S.J. and Haltiwanger, J., 1992. "Gross Job Creation, Gross Job Destruction, and Employment Reallocation," Quarterly Journal of Economics, 107, 819-63.

[15] Davis, D., and Weinstein,D., 2002. "Bones, Bombs, and Break Points: The Geography of Economic Activity," American Economic Review, 92, 1269-1289.

[16] Duranton, Gilles, 2007. "Urban Evolutions: The Fast, the Slow, and the Still," American Economic Review, 97, 197-221.

[17] Duranton, Gilles and Henry Overman, 2008. "Exploring the Detailed Location Patterns of U.K. Manufacturing Industries Using Micro-Geographic Data," Journal of Regional Science, 48, 213243.

[18] Gabaix, X., 1999a. "Zipf's Law for Cities: An Explanation," Quarterly Journal of Economics, 114, 739-767.

[19] Gabaix, X., 1999b. "Zipf's Law and the Growth of Cities," American Economic Review, 89, 129-132.

[20] Garofalo, G.A. and Yamarik, S., 2002. "Regional Convergence: Evidence from a New State-by-State Capital Stock Series," Review of Economics and Statistics, 84, 316-323.

[21] Glaeser, E., Kolko, J., and Saiz, A., 2001. "Consumer City," Journal of Economic Geography, 1, $27-50$.

[22] Glaeser, E., Gyourko, J. and Saks, R., 2005. "Why Is Manhattan So Expensive? Regulation and the Rise in Housing Prices," Journal of Law and Economics, 48, 331-369.

[23] Hess, G.D. and Shin, K., 1997. "International and Intranational Business Cycles," Oxford Review of Economic Policy, 13, 93-109.

[24] Holmes, T., 2005. "The Location of Sales Offices and the Attraction of Cities," Journal of Political Economy, 113, 551-581.

[25] Holmes, T., and Stevens, J., 2002. "Geographic Concentration and Establishment Scale," Review of Economics and Statistics, 84, 682-690. 
[26] Holmes, T., and Stevens, J., 2004. "Spatial distribution of economic activities in North America," Handbook of Regional and Urban Economics, in: J. V. Henderson \& J. F. Thisse (ed.), V. 4, Chapter 63, 2797-2843, Elsevier.

[27] Lucas, R. E., 1987. Models of Business Cycles, Basil Blackwell.

[28] Lustig, H. and Van Nieuwerburgh, S., 2010. "How Much Does Household Collateral Constrain Regional Risk Sharing?," Review of Economic Dynamics, 13, 265-294.

[29] McGrattan, E. and Prescott, E., 2009. "Unmeasured Investment and the Puzzling U.S. Boom in the 1990s," Research Department Staff Report 369, Federal Reserve Bank of Minneapolis.

[30] Rappaport, J., 2007. "Moving to Nice Weather," Regional Science and Urban Economics, 37, 375398.

[31] Rappaport, J., 2008. "Consumption Amenities and City Population Density," Regional Science and Urban Economics, 38, 533-552.

[32] Rappaport, J., 2009. "The Increasing Importance of Quality of Life," Journal of Economic Geography, 9, 779-804.

[33] Rappaport, J. and Sachs, J. D., 2003. "The United States as a Coastal Nation," Journal of Economic Growth, 8, 5-46.

[34] Rossi-Hansberg, Esteban and Mark Wright, 2007. "Urban Structure and Growth," Review of Economic Studies, 74, 597-624.

[35] Storesletten, K., Telmer, C. and Yaron, A., 2001. "The Welfare Cost of Business Cycles Revisited: Finite Lives and Cyclical Variation in Idiosyncratic Risk," European Economic Review, 45, 1311-1339. 


\section{Cities with Largest Percentage Change in City Population Without Amenity Differences}

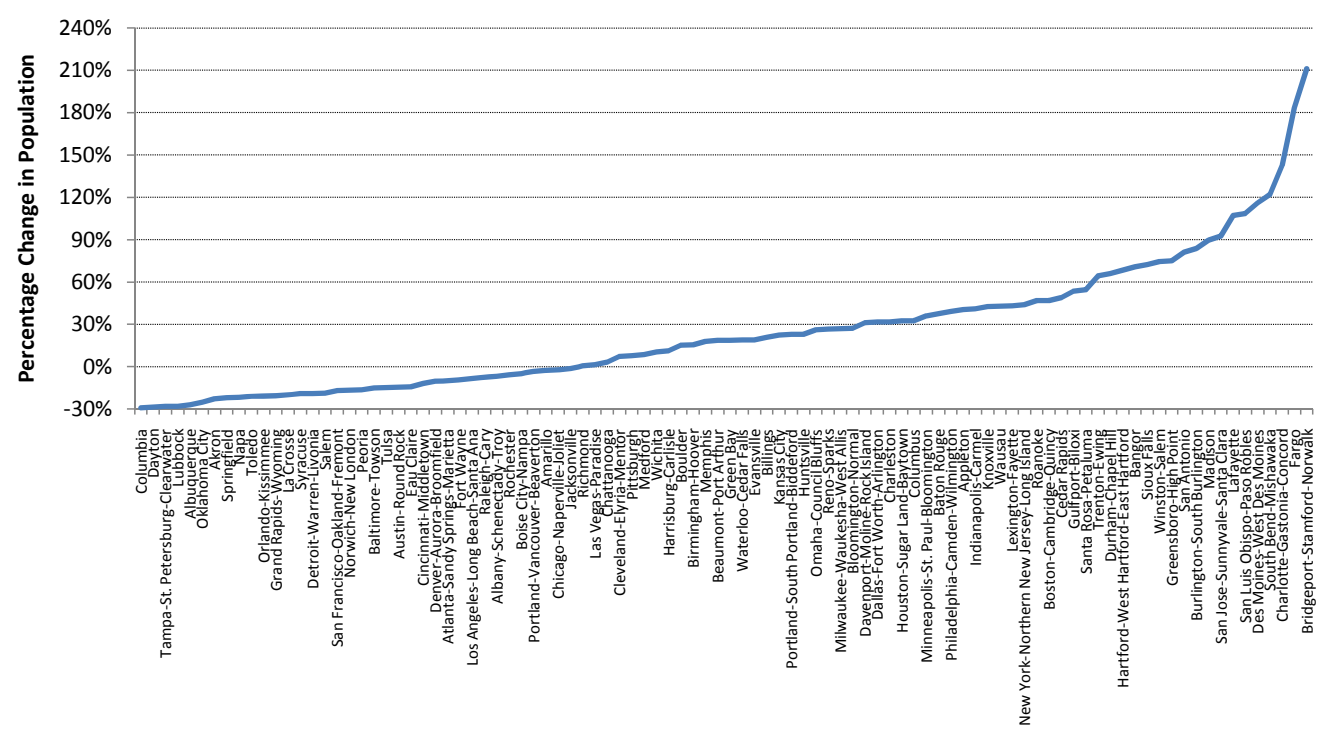

Cities with Smallest Percentage Change in City Population Without Amenity Differences

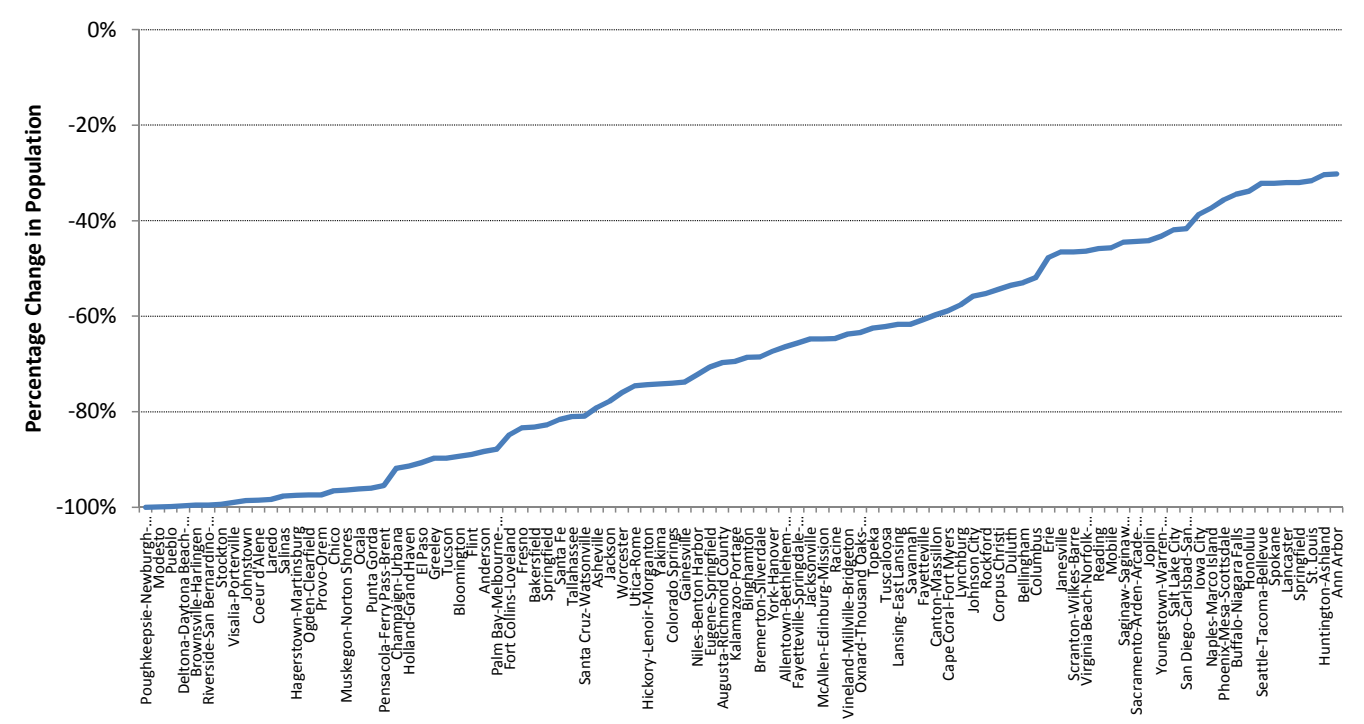

Figure A1: Changes in Population Sizes with Average Amenities 


\section{Cities with Largest Percentage Change in City Population Without Efficiency Differences}

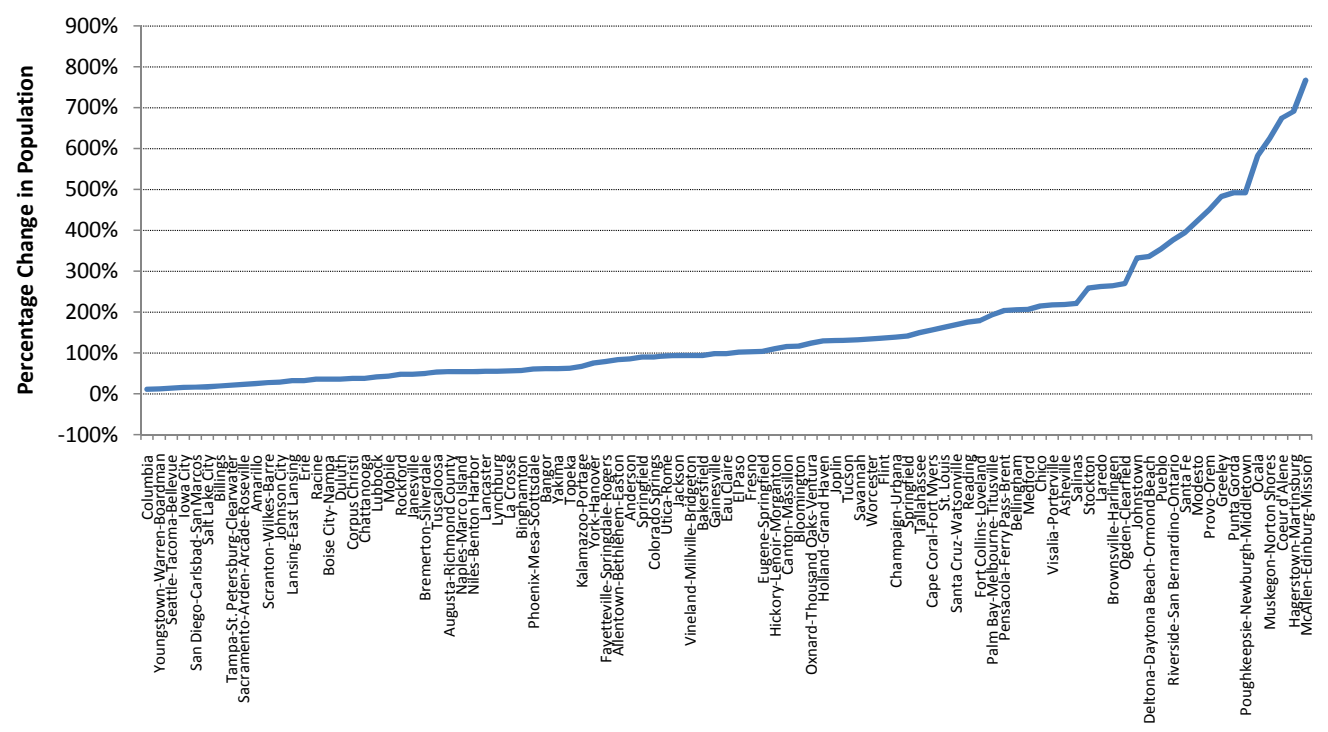

Cities with Smallest Percentage Change in City Population Without Efficiency Differences

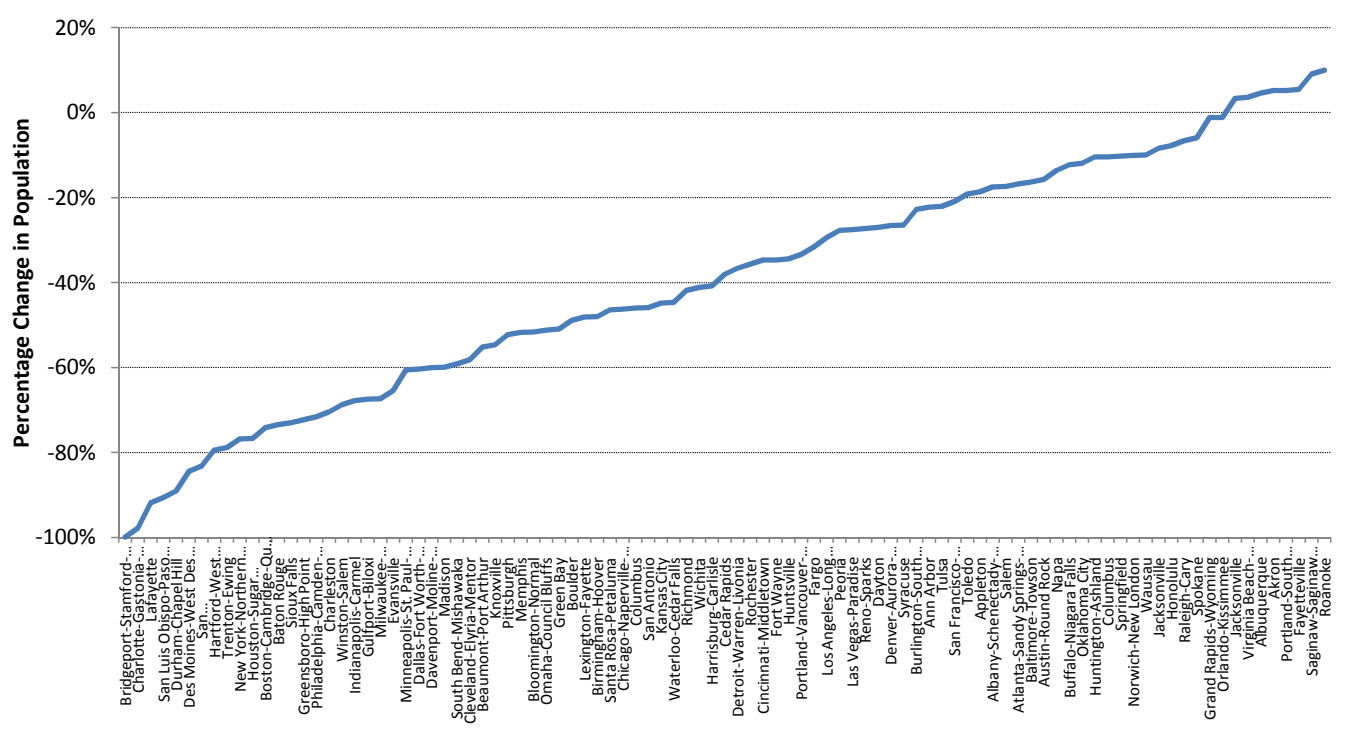

Figure A2: Changes in Population Sizes with Average Efficiency 
Cities with Largest Percentage Change in City Population Without Excessive Friction Differences

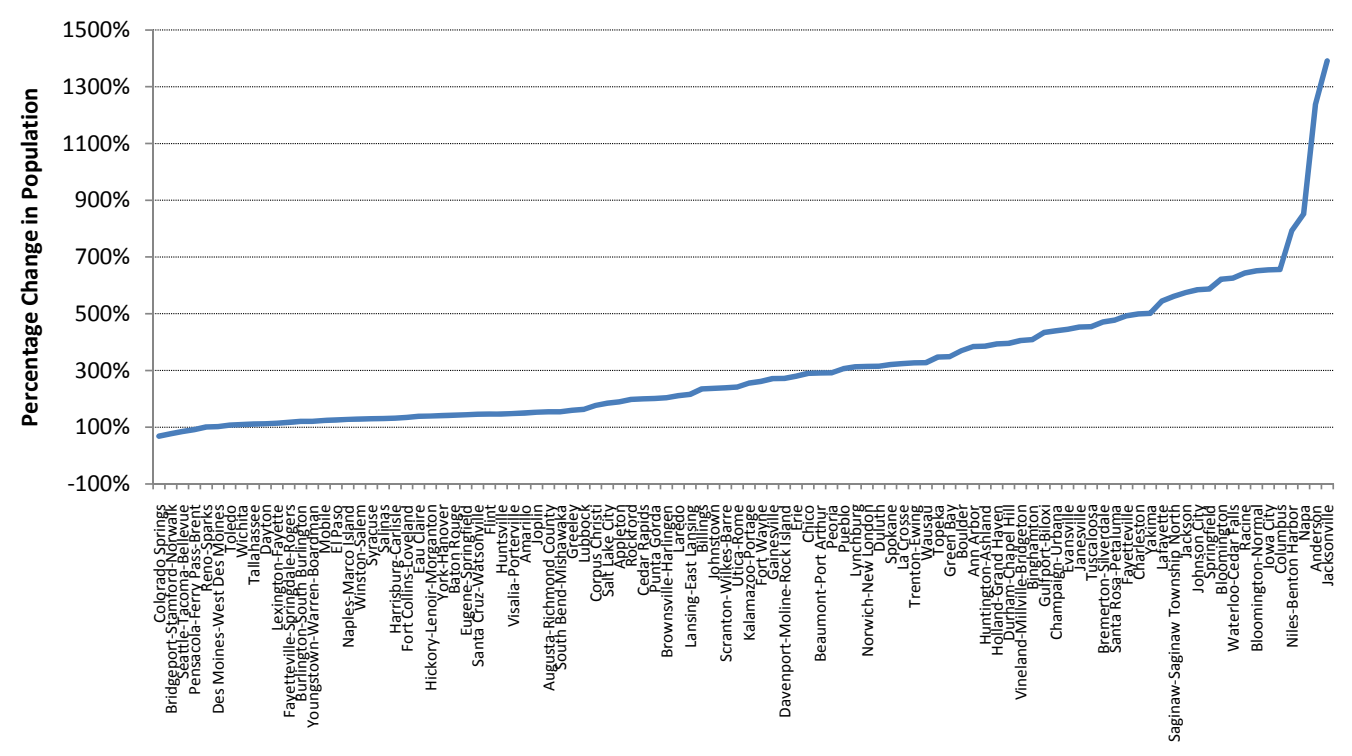

Cities with Smallest Percentage Change in City Population Without Excessive Friction Differences

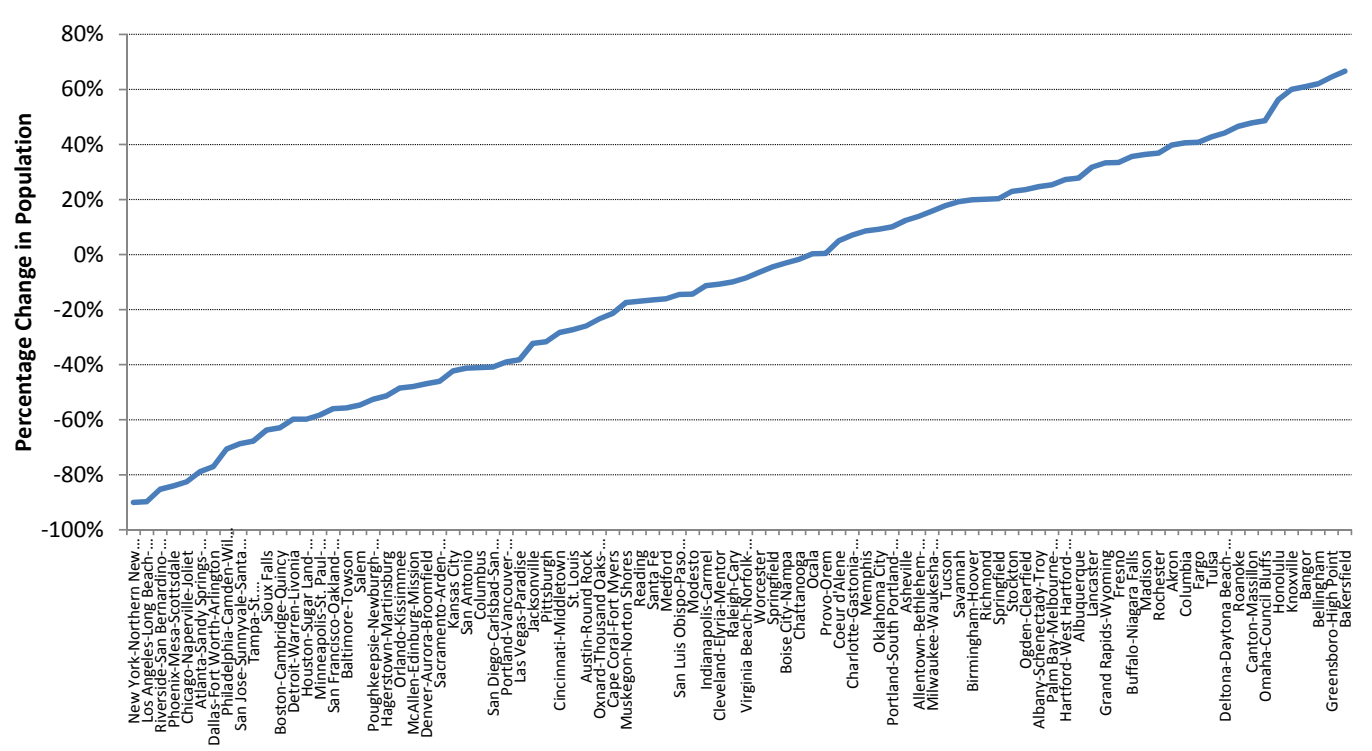

Figure A3: Changes in Population Sizes with Average Excessive Frictions 


\section{Cities with Largest Percentage Change in City Population}

Without Amenity Differences

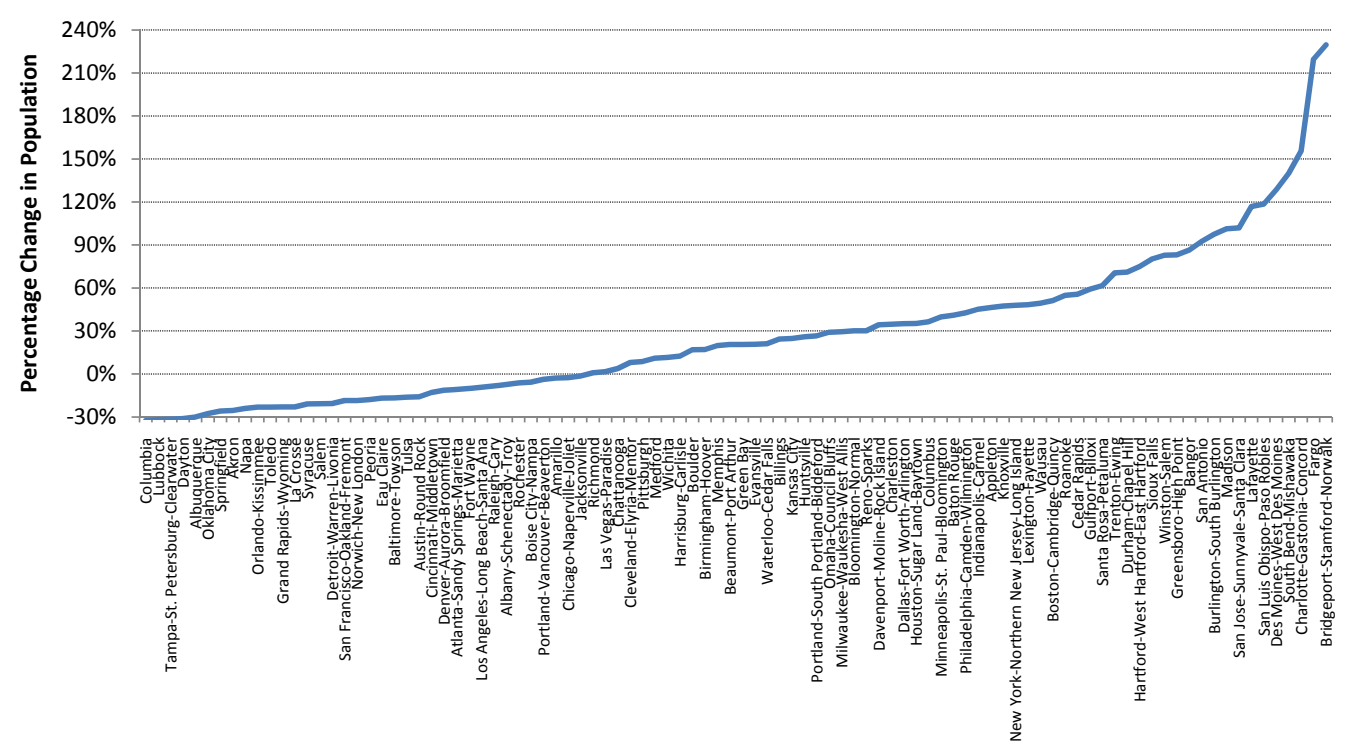

\section{Cities with Smallest Percentage Change in City Population Without Amenity Differences}

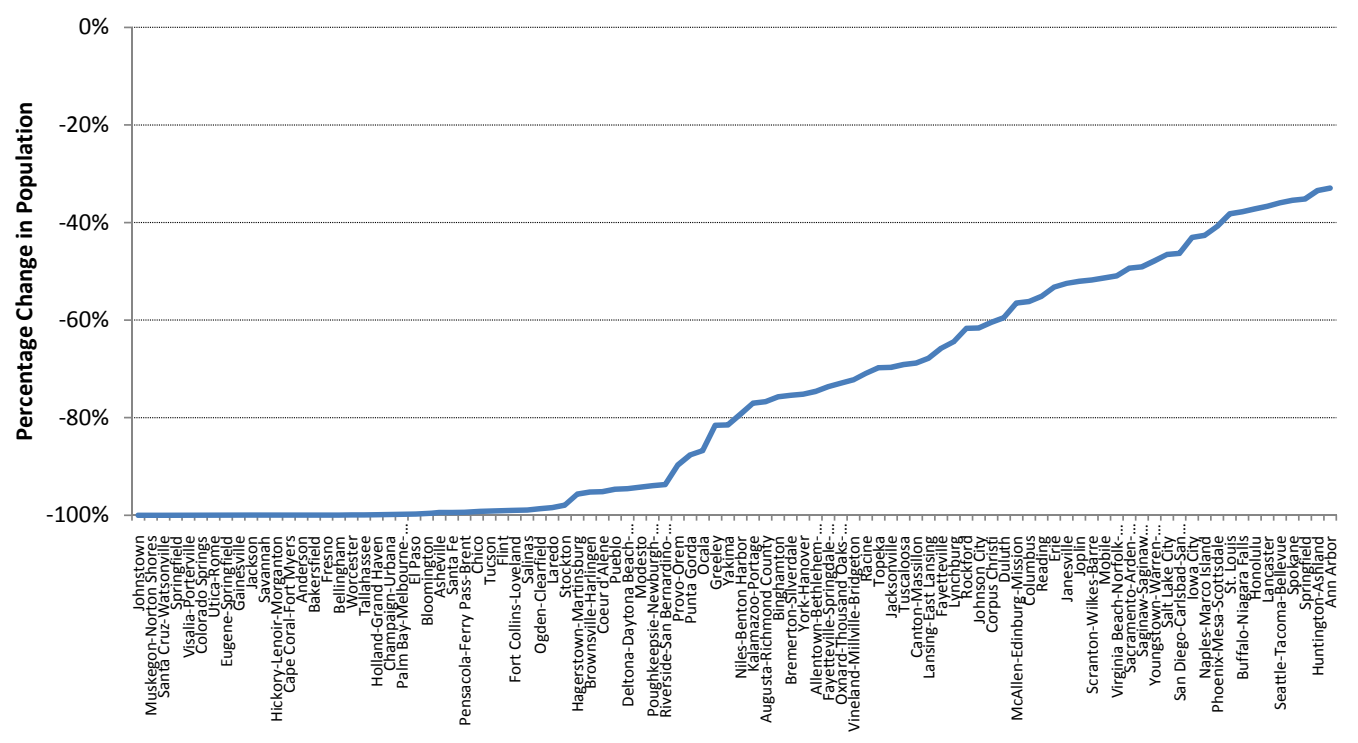

Figure A4: Changes in Population Sizes with Average Amenities (with Externalities) 


\section{Cities with Largest Percentage Change in City Population Without Efficiency Differences}

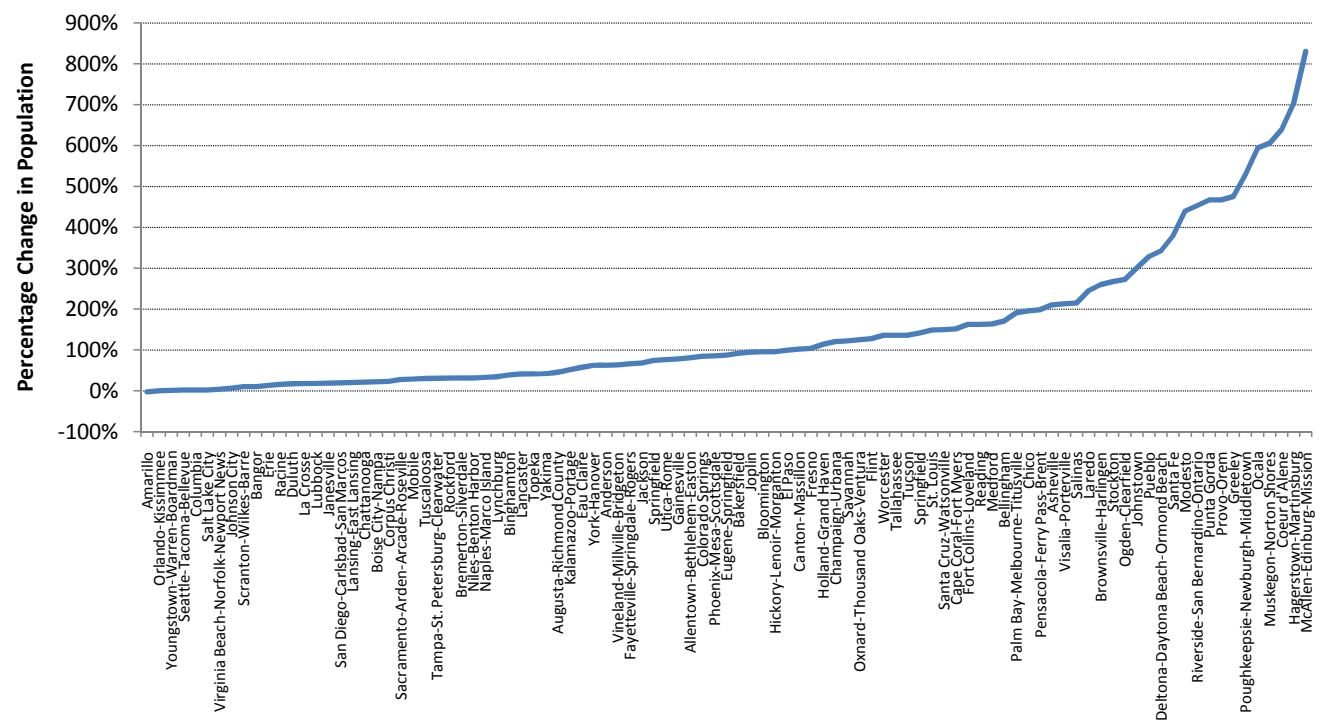

\section{Cities with Smallest Percentage Change in City Population}

Without Efficiency Differences

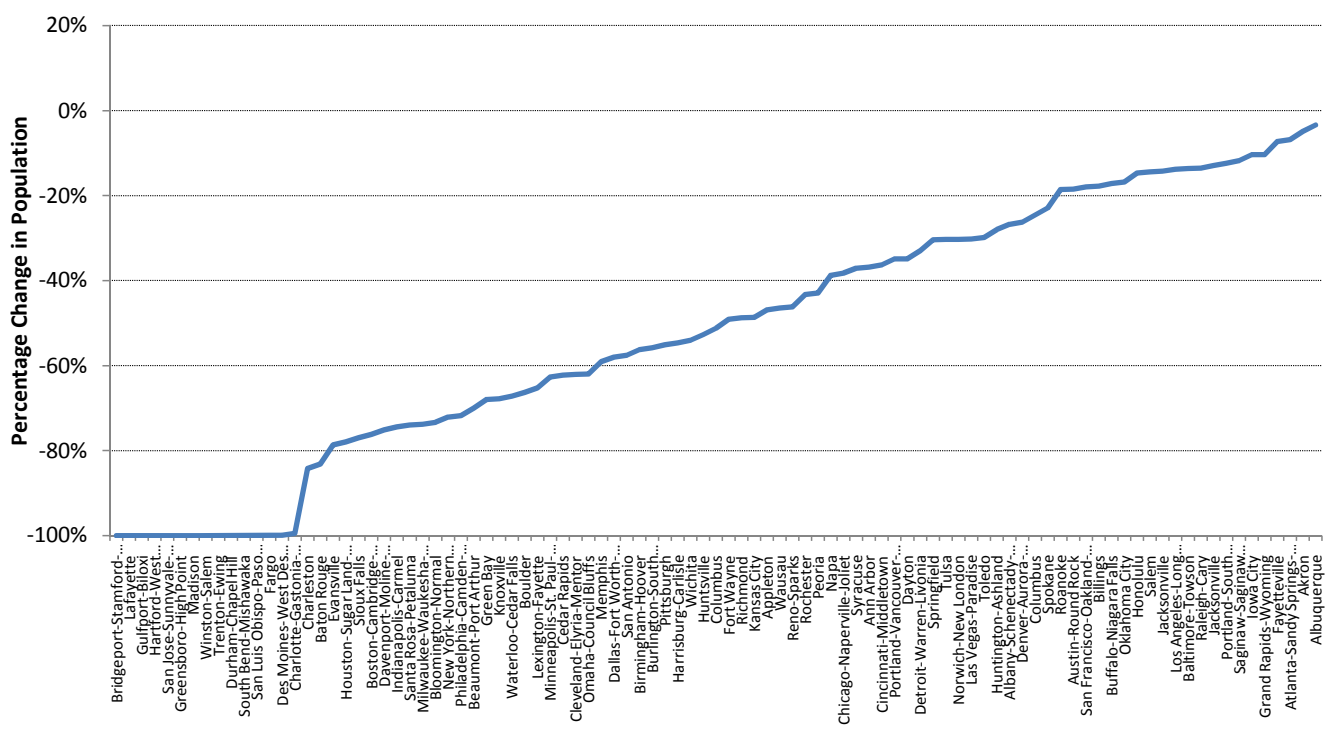

Figure A5: Changes in Population Sizes with Average Efficiency (with Externalities) 
Cities with Largest Percentage Change in City Population Without Excessive Friction Differences

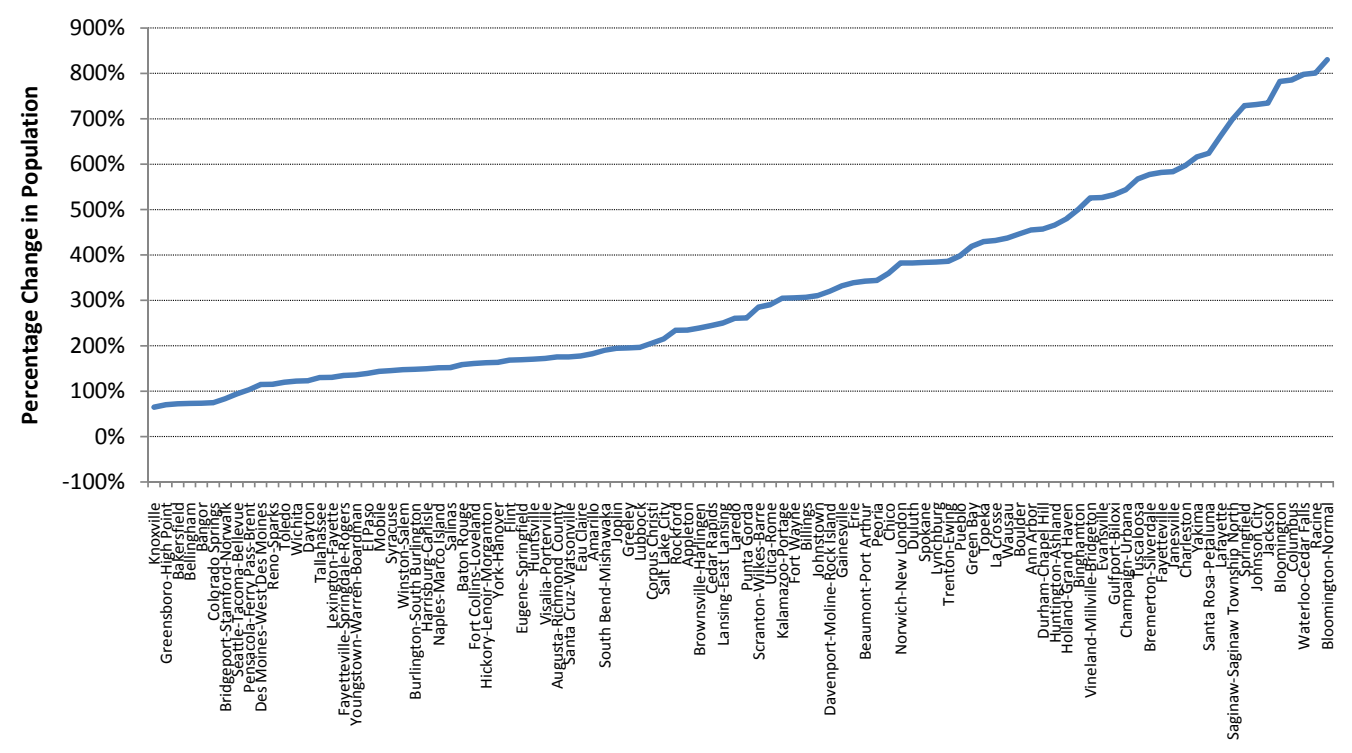

Cities with Smallest Percentage Change in City Population Without Excessive Friction Differences

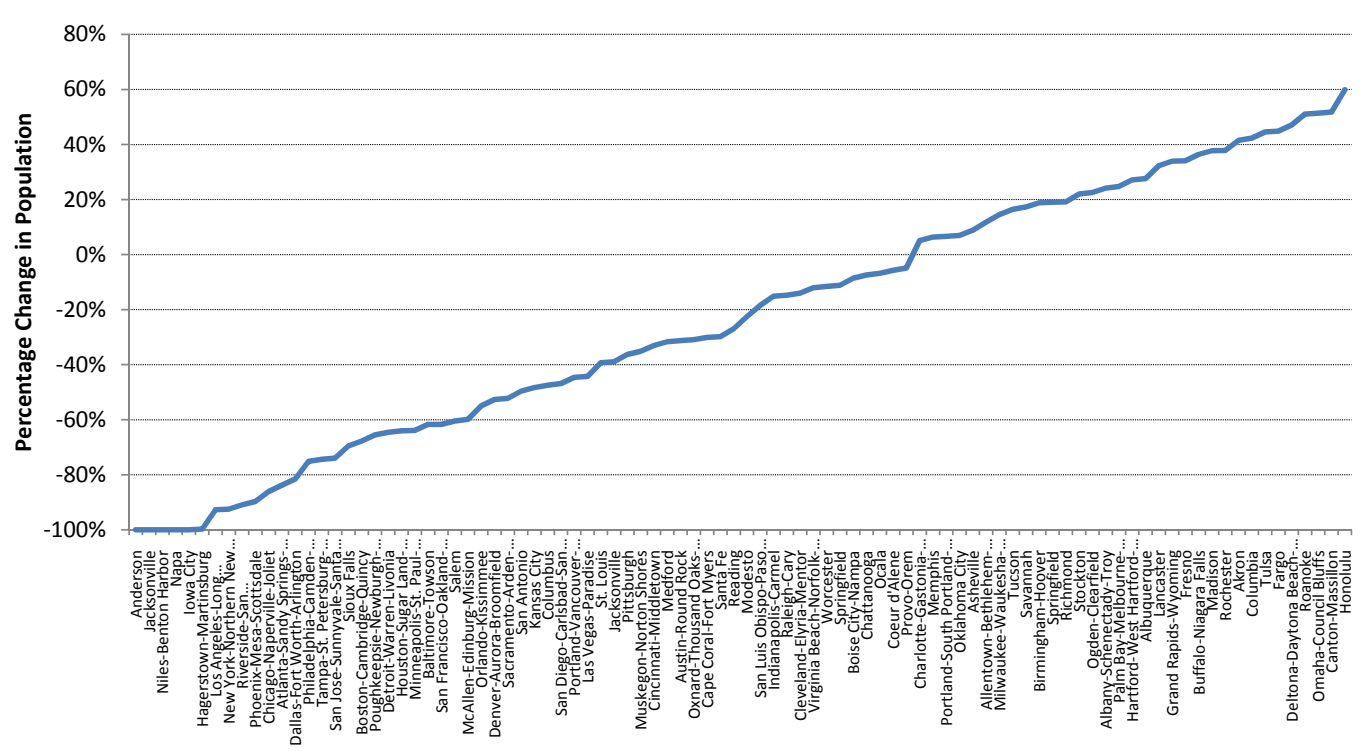

Figure A6: Changes in Population Sizes with Average Excessive Frictions (with Externalities) 
Without Differences in Amenities:

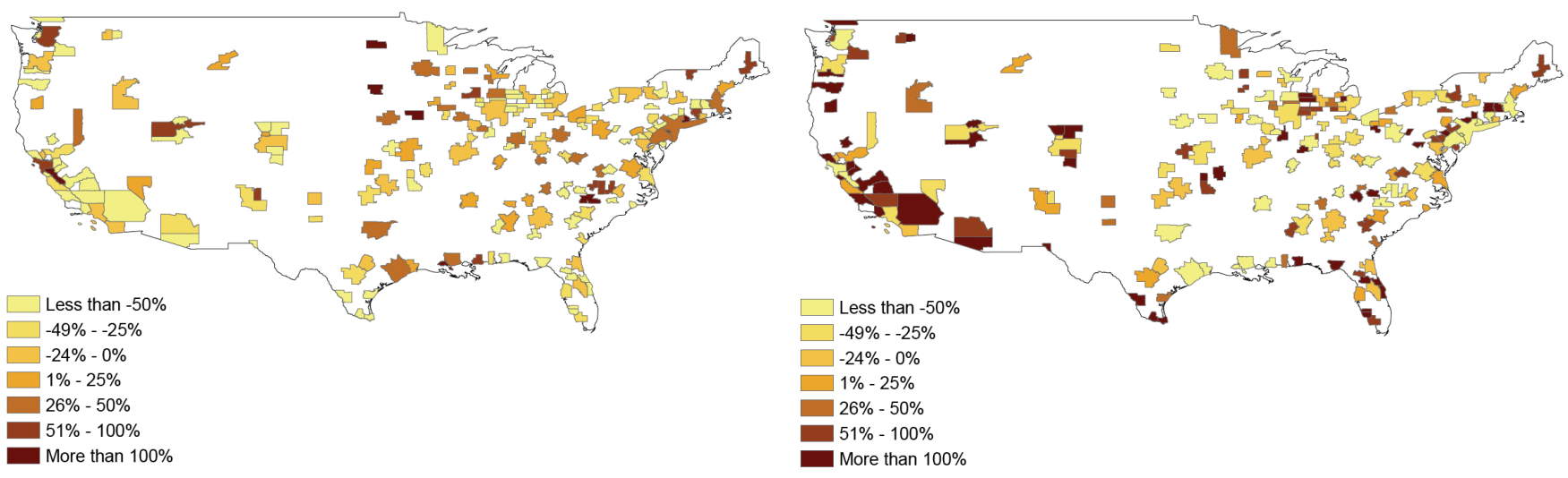

Without Differences in Excessive Frictions:

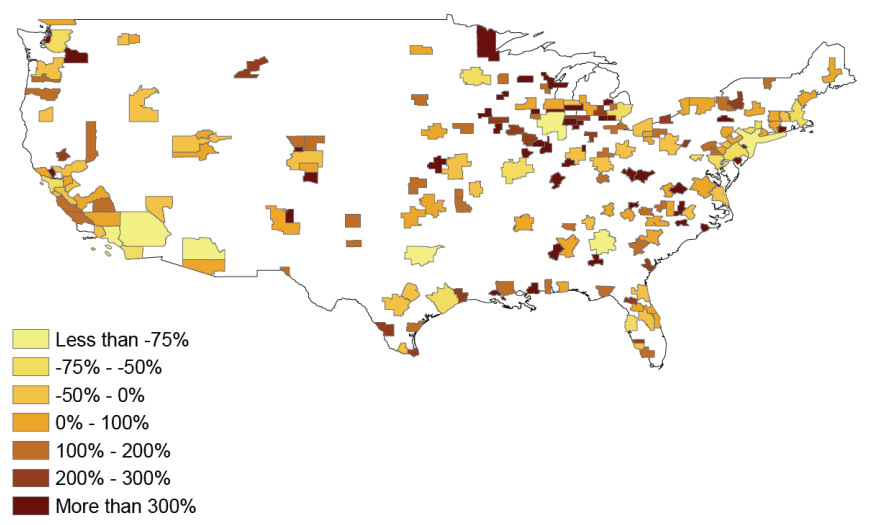

Figure A7: Maps of Changes in Population Sizes 
Without Differences in Amenities:

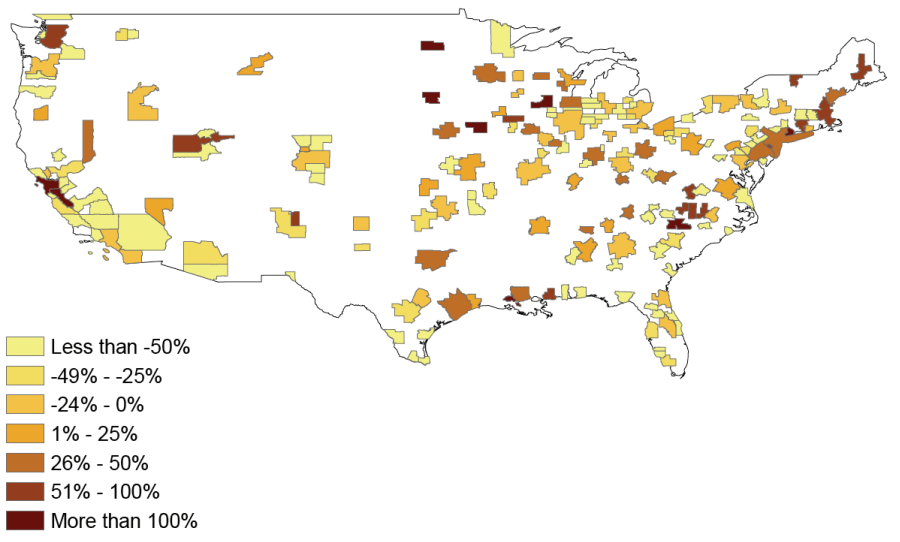

Without Differences in Efficiency:

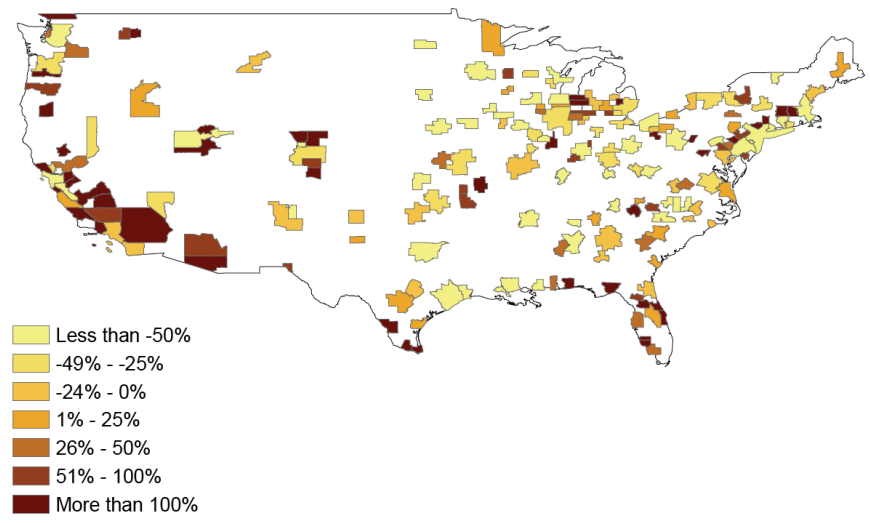

Without Differences in Excessive Frictions:

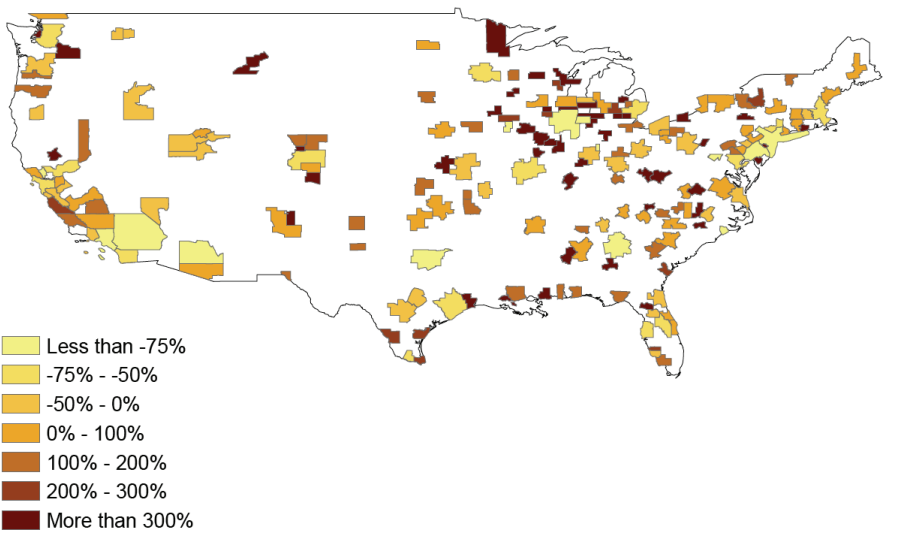

Figure A8: Maps of Changes in Population Sizes with Externalities, $\omega=0.02$ 


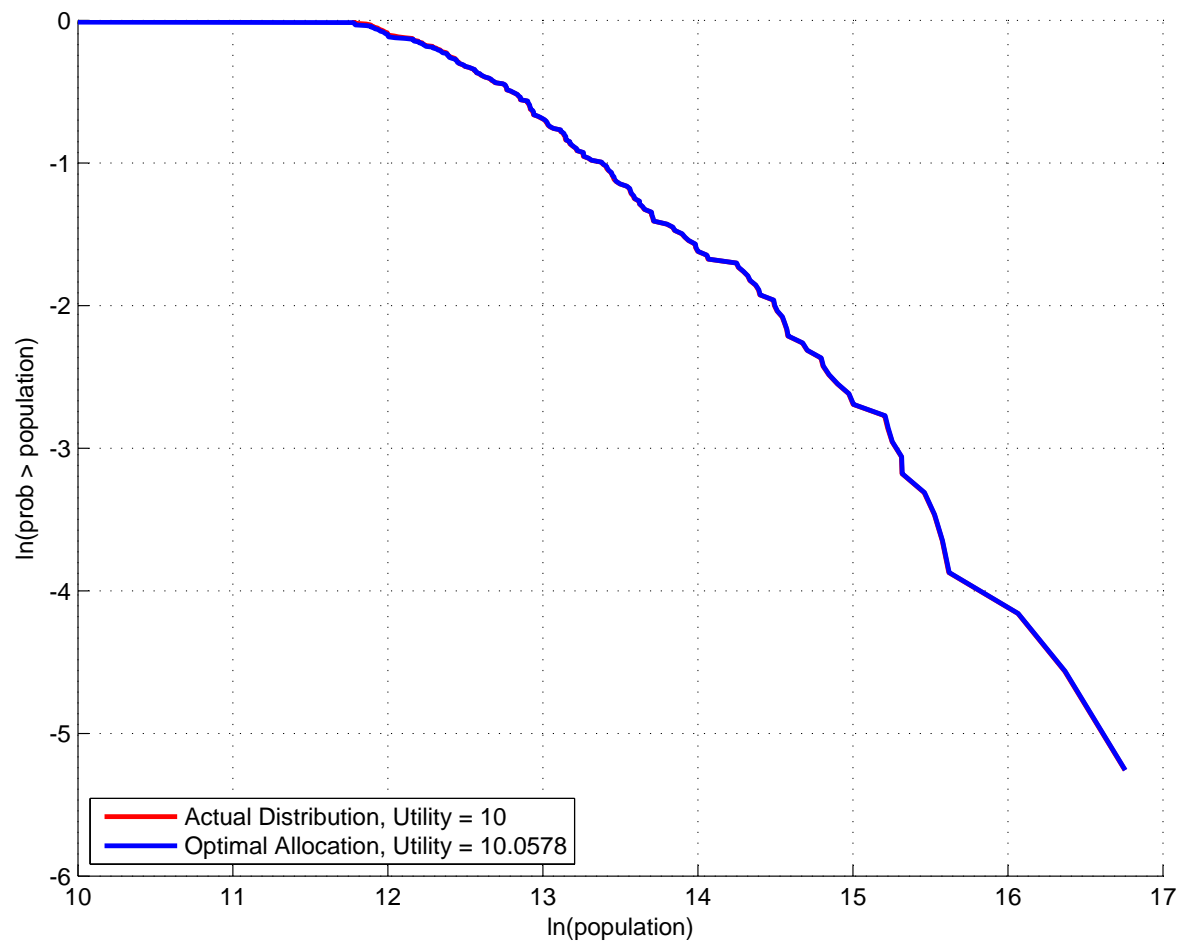

Figure A10: Optimal Allocation with Externalities, $\omega=0.02$

\section{APPENDIX B: DATA APPENDIX}

\section{B.1 United States}

This section provides a detailed description of the U.S. metropolitan data we use.

Unit of observation. The unit of observation is the metropolitan statistical area (MSA). A metropolitan statistical area is a collection of counties with at least one urbanized area of 50,000 or more inhabitants. We use data from 2005 to 2008. Going further back in time is complex, since the definition of MSAs changed in 2003, and there was a subsequent lag in the adoption of the new definitions. More recent data (for 2009) are not available yet for some of the relevant variables.

Production. Measured by Gross Domestic Product by Metropolitan Area. Source: Bureau of Economic Analysis, Regional Economic Accounts. 
Private consumption. The measure of consumption used to compute the labor wedge is private consumption. There are no ready-to-use data on private consumption at the metropolitan area level. We start by decomposing private consumption into private consumption net of housing services and private consumption of housing services.

We proxy private consumption net of housing services by retail earnings. In particular, we use retail earnings (at the MSA level) multiplied by private consumption net of housing (at the U.S. level) divided by retail earnings (at the U.S. level). Data on retail earnings are defined as personal earnings from retail trade and come from the Bureau of Economic Analysis Regional Economic Accounts, Table CA05. Data on private consumption net of housing come from the Bureau of Economic Analysis National Income and Product Accounts (NIPA), Table 2.3.5. In using this proxy, we follow the literature on interregional risk sharingm, which has used retail sales as a proxy for private consumption (Asdrubali et al., 1996, Hess and Shin, 1997, Lustig and Van Nieuwerburgh, 2010). Note that those papers use retail sales, rather than retail earnings, by using data from the Survey of Buying Power published by Sales \& Marketing Management. However, that survey got interrupted during the period 2006-2008. Both proxies are very similar though. For 2005 and 2008 the correlation between retail earnings and retail sales at the MSA level is about 0.80. In addition, the correlation between private consumption and retail earnings at the U.S. level for the years $2001-2008$ is 0.99 .

We proxy private consumption of housing services by taking the sum of aggregate gross rent of renter-occupied housing and the rental value of the aggregate value of owner-occupied housing. Both variables are available at the MSA level and come from the annual American Community Survey run by the U.S. Census Bureau. To compute the rental value of owner-occupied housing, we assume that the aggregate value of owner-occupied housing is the discounted sum of future rental flows, taking into account depreciation. The rental value of owner-occupied housing is then computed as the aggregate value of owner-occupied housing multiplied by $r+\delta$ and divided by $1+r$. For the benchmark calculation, we take $r=\delta=0.02$, as in the rest of the paper (see Table 1 ).

Capital stock. Again, there are no ready-to-use capital stock data at the MSA level. We start by decomposing the capital stock into non-residential and residential capital.

We proxy non-residential capital at the MSA level by using sectoral non-residential capital stock data at the U.S. level and allocating it to the different MSAs as a function of their sectoral weights. This is similar to the approach taken by Garofalo and Yamarik (2002) when estimating state capital 
stocks. Sectoral non-residential capital stock data come from the National Economic Accounts from the BEA. We take the sum of private and public capital. For private non-residential capital we take current-cost net stock of private fixed assets by industry (Table 3.1ES); for public non-residential capital we take current-cost net stock of government fixed assets at both the federal level and the state and local level (Table 7.1B). We then allocate the sectoral capital stock to the MSAs as a function of their shares of sectoral earnings. In particular, capital stock in sector $s$ in MSA $i$ is computed as the capital stock in sector $s$ in the U.S. multiplied by earnings in sector $s$ in MSA $i$ divided by earnings in sector $s$ in the U.S. Data on sectoral earnings both at the MSA and the U.S. levels come from the Regional Economic Accounts of the Bureau of Economic Analysis (Table CA05N).

Non-residential capital at the MSA level is easier to come by. We take the sum of the aggregate value of renter-occupied and owner-occupied housing. In the case of owner-occupied housing, that information is available from the American Community Survey of the U.S. Census Bureau. In the case of renter-occupied housing, the same data source gives information on the aggregate gross rent. This allows us to compute the value of rental-occupied housing as the aggregate gross rent multiplied by $1+r$ divided by $r+\delta$. This assumes, as before, that the value of housing is equal to the discounted sum of future rental streams, where future rental streams are the same as today's rental stream corrected for depreciation.

Hours worked. To compute average hours worked we take the total hours worked divided by the population 16 years old and above. We use data from the Current Population Survey (CPS) and compute total hours worked at the MSA level by summing up the total hours worked by individuals (weighted by their representativeness in the sample) and then dividing them by all individuals aged 16 and above in the sample (weighted by their representativeness in the sample). To limit errors due to small sample problems, we leave out MSAs that have information on less than 50 individuals. The share of time worked is then equal to the average hours worked per day divided by 14 .

Housing rental prices. As a measure for housing rental prices, we take the median gross rent of rental-occupied housing. Data at the MSA level are available from the American Community Survey from the U.S. Census Bureau. 


\section{B.2 China}

This section provides a detailed description of the Chinese city-level data we use.

Unit of observation. The unit of observation is Districts under Prefecture-Level Cities. This corresponds to the urban part of Prefecture-Level Cities, sometimes referred to as the city proper. Note that Prefecture-Level Cities cover the entire Chinese geography and include both the urban parts (proxied for by Districts under Prefecture-Level Cities) and the rural hinterlands. We focus on 2005 and have data on 212 cities.

Production. Measured by Gross Domestic Product at the level of Districts under Prefecture-Level Cities. Source: China City Statistics, China Data Center.

Private consumption. To compute private consumption at the level of Districts under PrefectureLevel Cities, we multiply retail sales of consumer goods at the level of Districts under Prefecture-Level Cities by the ratio of final consumption expenditure to total retail sales of consumer goods at the national level. Source: China City Statistics and National Statistics, China Data Center.

Population. Population and Population aged 15 years and above. Source: China City Statistics, China Data Center.

Hours worked. To compute average hours worked we take the total hours worked divided by the population 15 years old and above. We use the 2005 1\% Population Survey to get data on the population aged 15 years and above, population employed, and average hours worked by the employed. We then multiply population employed by average hours worked by employed and divide it by the population 15 years and above. These data are available for most Prefecture-Level Cities but often not for Districts under Prefecture-Level Cities. In order not to lose too many observations, we use the data at the level of Prefecture-Level Cities.

Parameter values. Bai et al. (2006) provide time series estimates for the capital share of income and for the real interest rate. Taking the average for 2000-2005, we set $\theta=0.5221$ and $r=0.2008$. To be consistent with the case of the U.S., where we took $\psi$ from McGrattan and Prescott (2009), we use the same formula as they do: $\psi=\frac{\left(1-\tau_{h}\right)(1-\theta)(1-h)}{\left.1+\tau_{c}\right) c h}$, where $c$ is consumption per capita (data defined above), $h$ are hours worked as share of total hours (average hours worked per year as defined 
above divided by 5110), $\tau_{h}$ is the tax rate on labor (defined as personal income tax as a share of personal income) and $\tau_{c}$ the tax rate on consumption (defined as the sum of consumption tax and value added tax as a share of total consumption expenditures). The data needed to compute these tax rates come from the National Bureau of Statistics of China and are for 2004. This gives us a value $\psi=1.5247$. 